NBSIR 82-2634

\title{
Workshop on Combustion Product Toxicity Summary of Presentations, September 10, 1982
}

U.S. DEPARTMENT OF COMMERCE

National Bureau of Standards

National Engineering Laboratory

Center for Fire Research

Washington, DC 20234

November 1982

Issued January 1983

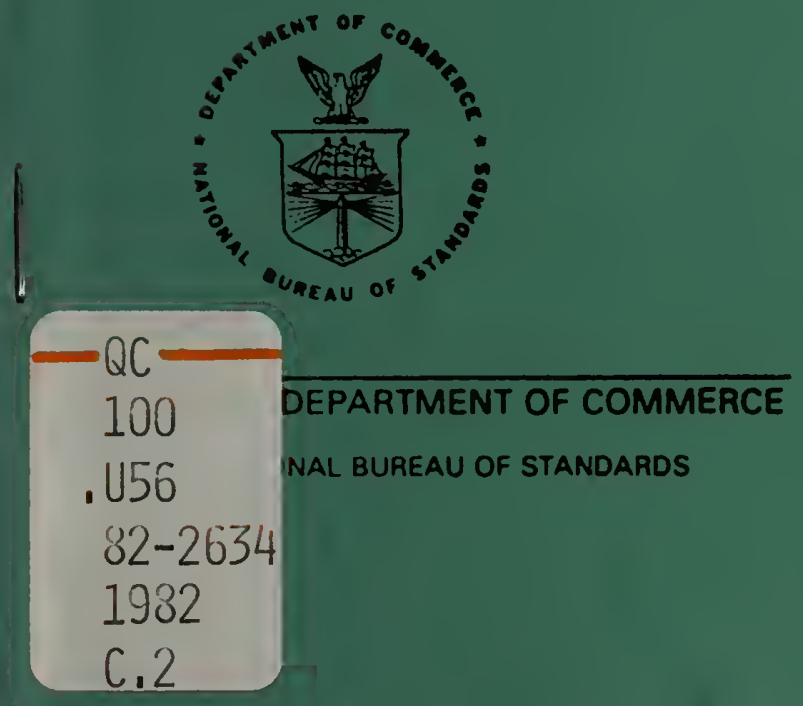





\title{
WORKSHOP ON COMBUSTION PRODUCT
} TOXICITY SUMMARY OF PRESENTATIONS. SEPTEMBER 10, 1982

\author{
J. E. Snell, B. C. Levin, A. J. Fowell
}

U.S. DEPARTMENT OF COMMERCE National Bureau of Standards National Engineering Laboratory Center for Fire Research Washington, DC 20234

November 1982

Issued January 1983 


\author{
Workshop on Combustion Product Toxicity \\ Summary of Presentations \\ September 10, 1982
}

J. E. Snell, B. C. Levin, A. J. Fowell

\title{
FOREWORD
}

This publication is a summary of presentations given September 10 , 1982, at a Workshop on Combustion Product Toxicity.

Publicity on fire deaths caused by smoke and toxic gases has given impetus to a number of state legislatures to consider requiring material toxicity provisions in building codes and other regulations. The National Bureau of Standards recently published a technical report describing the development of a test method for the assessment of the acute inhalation toxicity of combustion products. This test method is intended primarily for research and; fr preliminary screening purposes by product researchers and material manufacturers in developing and evaluating materials. The test method is not intended to be used by itself in evaluating the suitability of a material for specific application since additional factors must be considered.

Nonetheless, a number of fire, building code, and other regulatory officials, as well as industry and association members, who have responsibilities relating to fire hazard assessment may benefit from learning more about the test method, the background to its development, and limitations on its appropriate use, and the relevance of this work to code, regulatory, or material selection decisions or provisions.

Therefore, the National Bureau of Standards sponsored a half-day workshop on combustion product toxicity, 9:00 a.m. - 12:00 noon, Friday, September 10, 1982, at NBS in Gaithersburg, Maryland. The purpose of this workshop was to brief fire code and building officials and others on the NBS test method for assessing acute inhalation toxicity of combustion products and to provide an opportunity for discussion of its appropriate use.

The agenda of the workshop is presented on page $v$. The presentations are published here in the order they appear on the agenda. 
TABLE OF CONTENTS

$\underline{\text { Page }}$

FOREWORD . . . . . . . . . . . . . . . . . . . . .

AGENDA . . . . . . . . . . . . . . . . . . . . . . .

PRESENTATIONS :

"Fire Hazard Assessment and Combustion Product Toxic1ty--An

Overview of the Context", Jack E. Sne11

"NBS Protocol/Test Method for Assessment of the Acute Inhalation Toxicity of Combustion Products", Barbara C. Levin......

"Hazard Assessment--Review of Research in Progress and Planned",

APPENDIX - ATTENDANCE LIST . . . . . . . . . . . . . . 


\section{WORKSHOP ON COMBUSTION PRODUCT TOXICITY \\ National Bureau of Standards \\ Green Auditorium}

September 10, 1982

AGENDA
Samue1 Kramer Deputy Director-Programs National Engineering Lab

Jack E. Snell, Director CFR

Barbara C. Levin, Head Fire Toxicology, CFR

Andrew J. Fowell, Chief Fire Safety Technology Division, CFR

Jack E. Snel1 - Moderator

11:15 Question \& Answer Session

\section{2:00 Adjourn}



Fire Hazard Assessment and Combustion Product

Toxicity--An Overview of the Context

Jack E. Snell

Good morning ladies and gentlemen. It's a pleasure for me to have the opportunity to discuss this important topic with you. I'm advised I should say at the very outset that our presentations are being video taped and the questions and answers recorded so that we can make this information available to others.

I've labored a great deal over how to begin this morning's program and have concluded it would be most fitting to begin with the "answer" or the "bottom line" as we see it and then successively through the balance of the program fill in and elaborate in detail. The purpose of this workshop is to provide interested parties in the fire community in general and particularly building and regulatory code officials a progress report on the Center for Fire Research's work in combustion product toxicity. Specifically, we wish to clear the air of any question or misunderstanding concerning NBSIR 82-2532 entitled, "Further Development of a Test Method for the Assessment of the Acute Inhalation Toxicity of Combustion Products," a copy of which you a11 now have.

And now here it comes, this is what we see as the bottom line. The test method described in this report is primarily intended for research and preliminary screening purposes for use by product researchers and material manufacturers in developing and evaluating materials. It is not suitable for use by itself for evaluating the fire safety of materials in use since a number of additional factors must be considered in a specific situation. Note the words "further development" in the title of this report. This simply denotes the fact that this is not the first and certainly is not the last report or word from us on this topic. Further development and evaluation of this test method and, in our view, all others currently available is necessary to determine their suitability or utility for regulatory purposes presuming the intent there of course, is fire-safe material/product design, selection, or evaluation. 
Please don't be mislead by these remarks. We are concerned about combustion product toxicity. However, we are much more intent upon broadening our understanding of all the principal determinants of the real threats or hazards posed by fire and the development of practicable tools for your use in dealing with them. It's our view that it will be mutually beneficial to share with those of you in the regulatory community as well as those in industry, our thinking on the technical issues that remain to be resolved regarding combustion product toxicity in the broader context of fire hazard assessment, and our current and planned research on these topics. Thus, even though we make no claim of offering a complete or easy solution to your current problems, we do believe this information will be of practical use to you, now.

Therefore, it is our hope that each of you will leave this meeting with a number of things. First, a clear understanding of what the test method is, what it does and does not address, our views on its appropriate use, and a copy of NBSIR 82-2532. Further, we hope you'11 have a clear understanding of our plans for future research in this area. Also, we hope to answer your questions. If we don't answer them this morning, we' 11 be sure to get the answers to you. Finally, we have asked each of you to fill out a registration card. It's our intent to send each of you a brief summary of the presentations of this morning for your further reference and also a list of all the folks here with their affiliation for your use and reference in getting the further information you may need to address the question of hazard assessment in a specific design problem or context.

For our part we hope to gain from this meeting a clear perception of the technical and measurement needs and concerns that you have so that to the extent possible within our resource limitations our efforts are responsive to them.

\section{Center for Fire Research Role in Combustion Toxic1ty Research}

The National Bureau of Standards has been involved in fire research from its very beginning. The Fire Prevention and Control Act of 1974 clearly dictated that the focus of the Center for Fire Research should be 
on developing greater understanding of fire phenomena, and providing the scientific and technical basis for development of sharper tools for resolving the serious problem of fire in this country. From that time we have been involved in combustion toxicity related work. This continued through the efforts of the Product Research Committee in which we worked with a number of groups in industry to broaden our understanding of materials' fire properties in general and toxicity in particular. In September 1980 we published a preliminary toxicity test method that subsequently was used in an interlaboratory evaluation and led to the development of the report we' 11 be discussing this morning. This effort has involved a large number of people. In fact, I'd venture to guess somewhere between $1 / 2$ to $2 / 3$ of those here this morning have been involved one way or another in the work we are talking about.

The topic of toxicity of combustion products from fires has been a matter of a great deal of publicity recently and indeed a matter of genuine concern within the fire community for quite sometime. For example, the National Fire Protection Association, and the National Institute of Building Sciences have recently held extensive meetings on this topic and have commissioned special task forces to review the facts and generate action recommendations for the fire community at large. In recent months a number of states have conducted hearings concerning the possible need for regulatory measures to address toxicity concerns. These include New York, New Mexico, and California. Also, CPSC and other federal agencies have expressed similar concerns regarding certain products and furnishings. Our intent this morning is not to attempt to replicate these efforts or to offer you a simple solution to the whole toxicity problem, but rather to provide a perspective on our scientific and technical efforts that may be useful to you in developing a lasting solution to this particular problem.

\section{Fire Hazard Assessment}

Now, let me say a few words about the context in which we see the toxicity issue. Firstly, and most importantly, fire safety usually involves tradeoffs (slide $1 *$ ). It's not a matter of safety at any cost. If that were 
the case, we'd all be wearing glass clothing and living in stone shelters as John Lyons is fond of saying. Rather, it's a matter of trade-offs between function, safety and cost. These trade-offs are made typically in the marketplace and in the governmental or regulatory contexts. For example, one of the model building codes defines an unsafe building as one which is a) structurally unsafe, b) has inadequate egress, c) presents a fire hazard, or d) is otherwise dangerous to human life. Our concern this morning is with fire hazard. Therefore, let's review our understanding of what we mean by this. The threat or hazard of fire to human life evolves over time through a sequence of events. I've listed on slide 2 a series of stages in the development of a fire and shown graphically at the bottom of this figure on the horizontal axis time and vertically some measure of fire intensity. The graph represents the process of evolution of a fire and the occurrence of various phases. It all begins, of course, with a pre-existing unsafe condition or practice, followed by the subsequent steps of fire growth and extinction. Alternatively, at some point an intervention strategy may be employed, e.g., extinguishment in which case, hopefully, the fire is knocked down before its intensity exceeds acceptable limits.

My point in going through this, perhaps simple-minded illustration, is simply this, our business is to provide the technical basis for interventions that work in reducing fire loss. It's our conviction that an orchestrated set of intervention strategies is essential. I've argued that it is socially unacceptable to create an environment in which no unsafe condition or practice exists. It would be nice, but it's unrealistic. By the same token it's unreasonable to expect that one single fire protection system or strategy is sufficient to deal with all possible fire threats and that it makes no difference what we put into a facility or what materials we use in its construction, furnishings, or finishings.

Now, let's take a closer look at what constitutes the threat of fire to human life. Slide 3. First of all we have the fire itself, the heat and flames, and the direct effect of them on building occupants. Secondly, we have the combustion products, generally smoke, and thirdly we have the overall event of the fire. Now we could think of each of these in terms of the threat that they pose to individuals who might be in the 
room of origin of the fire or elsewhere in the building in which fire might occur. We can think specifically what senses, physiologically are insulted by that aspect of the fire threat and develop means to characterize when and at what point and to what extent those senses are threatened. It is important for us to understand clearly the limits of tenability for each of those threats. Some of the main ones include: the effect of heat on our sense of feel; the irritant, toxic and visual effects of smoke; and the psychological/ physiological effects of the overall fire event in terms of stress on human occupants.

Also, we can consider the properties of materials or products involved in fire that give rise to these particular threats. For example, the pertinent parameters relating to heat and flames are fairly well understood. We have widely used test methods for flammability, ignitability, and combustibility, and we are working on measures of flame spread, and rate of heat release. These are measures we can use to understand the contribution of materials or products to the threat of fire to human life, and they can be used in the process of developing appropriate and effective intervention strategies. In the same way, we would like to understand the irritant threat of smoke. We know very little about that and are not all sure how to measure it. Those who have been repeatedly in direct contact with fire argue convincingly about its signficance and importance in disorienting or otherwise threatening occupants in terms of their ability to escape.

The focus of our attention this morning of course is on inhalation toxicity. Not only are the lethal aspects of smoke important, but also the intoxicating or incapacitating effects of smoke which result in occupants being subjected to further assault from other fire threats. Similarly, the effect of smoke on visual obscuration interferes with occupants' ability to escape. We have reasonable measures of optical density, and of smoke generation properties of materials, and these are now widely used and cited in codes. Finally, we have no measures of material or product properties that have been related to the overall psychological stress of a fire, yet we know it's important. 
Ideally, of course, we would like to have means to measure the fire properties of materials or systems that give rise to all of these threats. We would like to be able to predict the evolution of fire hazards in time and space, and use that understanding to test the effectiveness of various interventions.

Consider how, ideally, we might do this. I think we are all familiar with the personal computer, video games, and interactive graphics. So, let your imagination wander for just a moment and think about this problem in that context (slide 4). Ideally, we would like to be able to provide as input to the computer the design, contents, occupancy and use of a bullding including the major materials, furnishings and finishings, and the specific activity patterns and so on that are likely to take place in 1t. Secondly, we would like to be able to simulate a series of likely fire scenarios including ignition, what materials are involved and in what sequence, the responses of occupants and fire protection systems, etc., to the developing hazard. Thirdly, we would like to have a means to evaluate quantitatively the probable consequences of that simulation in terms of risk of life loss and injury, in terms of property loss, and in terms of cost, etc. Think about it. That would really be nice. That would provide us means to analyze actual fire data and probable fire scenarios; to test designs, materials, and furnishings, against those likely threats; and to test the performanceeffectiveness of various fire protection measures or systems in dealing with those threats. This capability is now within our reach.

In fact, this is the principal focus of the program of the Center for Fire Research. Dr. Fowell's presentation will deal in some depth with where we are now in terms of our ability to do just this. Before that, of course, we want to describe for you in detail the toxicity test method. In closing, let me just briefly recount in this broader context of fire hazard assessment that fire safe material selection and use (slide 5) is situation specific, it depends in a very significant way on the design of the material in question, its form, contents, structure, on other materials present and their properties, on fire protection systems and many other factors. 
Now, I'd like to introduce Dr. Barbara Levin who heads our Fire Toxicology Group. Barbara spent the last four years at NBS working on development of this test method, prior to that time she did postdoctoral work at the National Institute of Health in biochemistry and microbiology. She will be followed by $\mathrm{Dr}$. Andrew Fowell. Andy is Chief of the Fire Safety Technology Division of CFR. Andy is a mechanical engineer with a background in fluid mechanics and heat transfer research. He has 16 years of private sector research and product development experience. 

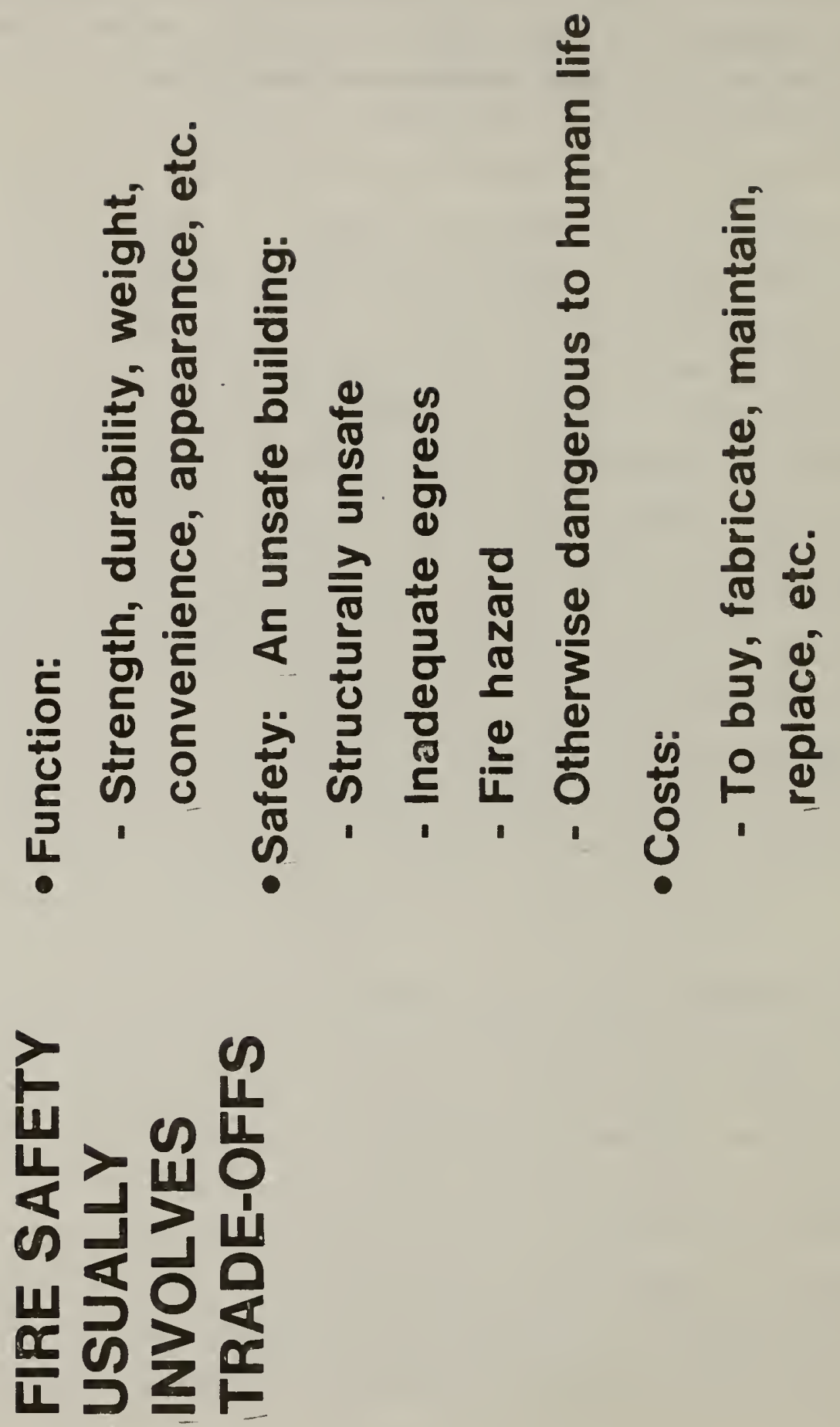


\section{FIRE HAZARD: Phases in Evolution}
A. Unsafe condition or practice
B. Ignition
C. Growth
D. Spread
E. Extinguishment
F. Recovery

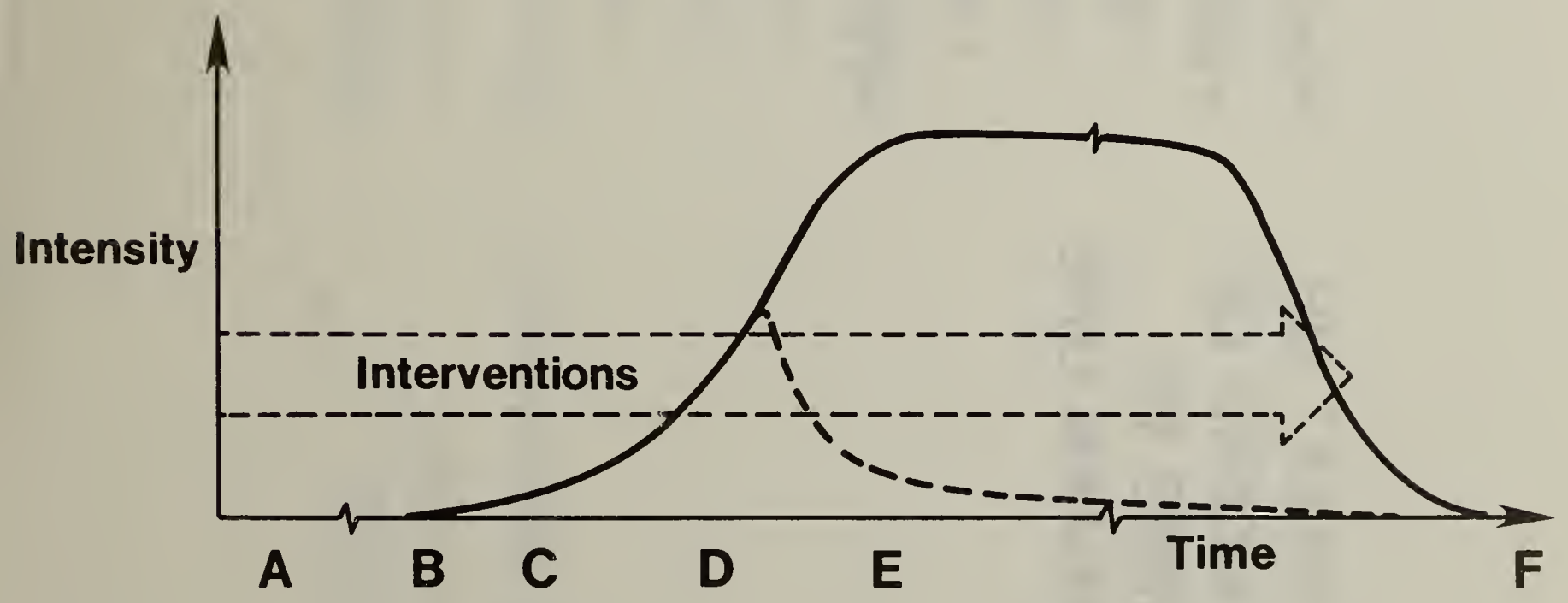




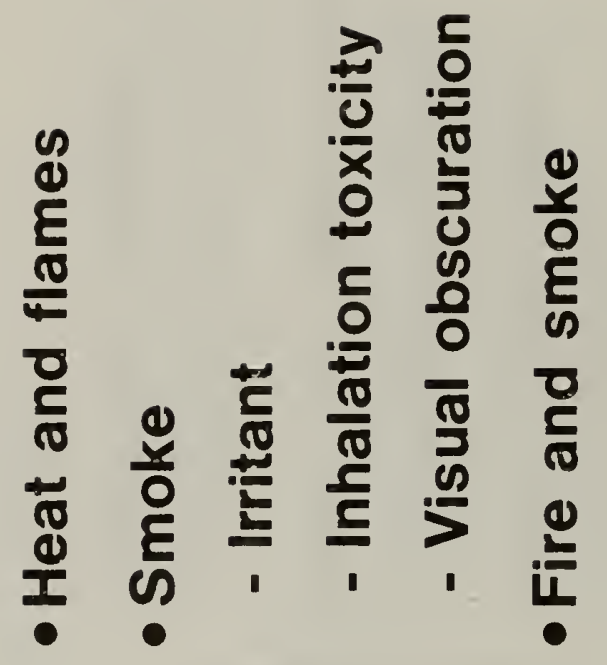

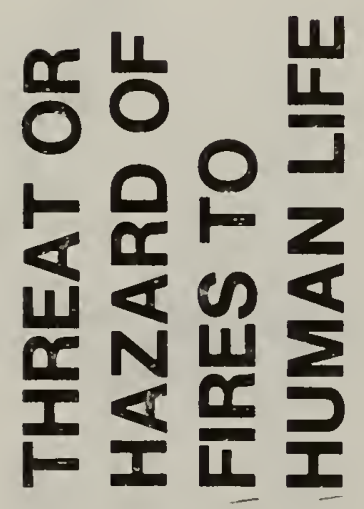



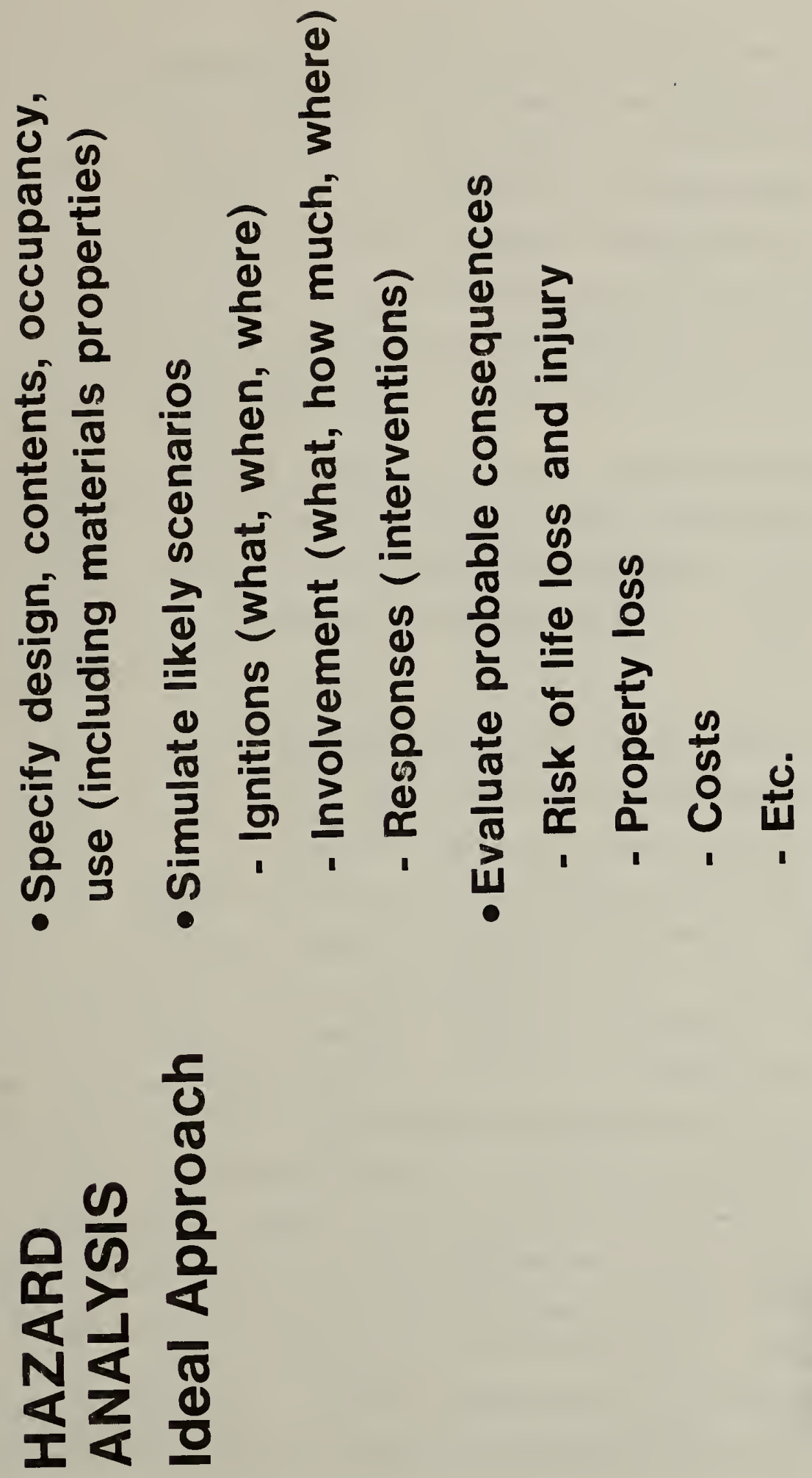
$\stackrel{\omega}{3}$

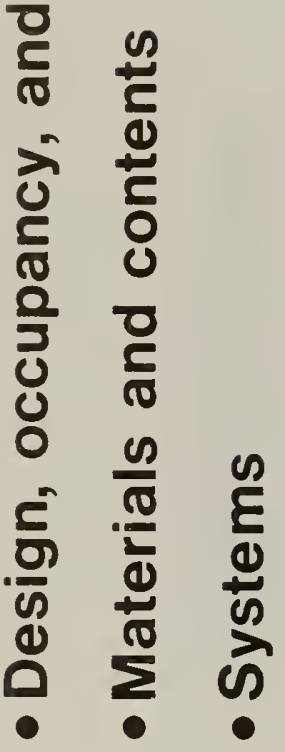

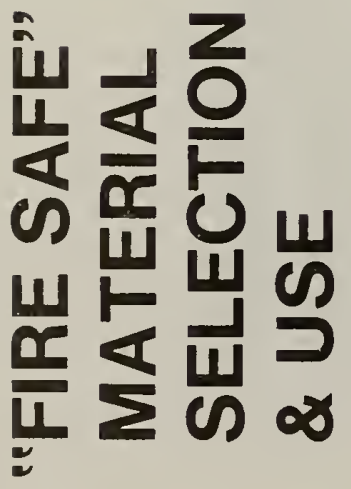


NBS Protocol/Test Method for Assessment of the Acute

Inhalation Toxicity of Combustion Products

Barbara C. Levin

Today I plan to describe the toxicity test method that we have developed here at the National Bureau of Standards and to discuss its use and its limitations. Most of what I plan to discuss is in the NBS report entitled "Further Development of a Test Method for the Assessment of the Acute Inhalation Toxicity of Combustion Products" (NBSIR 82-2532) which you received at registration. I will certainly not be able to provide all the information that is in the report, but, hopefully, this presentation will introduce you to the report and will answer any of your current questions.

The first slide shows the objective and use of the NBS toxicity test method. The objective is to assess the acute inhalation toxicity of combustion products under specified laboratory conditions. Its intended use is for research and preliminary screening purposes by product researchers and material manufacturers.

In slide 2, I will present some definitions to familiarize everyone with the terminology used both in the report and this presentation. "Acute toxicity" is defined as the harmful effects of a single short exposure to combustion products generated by the thermal degradation of materials. "Toxic hazard", on the other hand, is defined as the material and environmental conditions which increase the probability that a toxic atmosphere will occur and an injury will result. I'd like to emphasize that the test method only addresses acute toxicity. It does not address the problem of total toxic hazard. In this test method we also discuss "mass loading" which is the amount of material placed in the furnace and thermally degraded during the test itself. Another term is "auto-ignition temperature". This is defined as the lowest furnace temperature which causes a material sample, which is introduced into the cup furnace, to spontaneously ignite within 30 minutes. For each material, the toxicity test is performed at two different temperatures, a flaming temperature $-25^{\circ} \mathrm{C}$ above the autoignition temperature and a non-flaming temperature $-25^{\circ} \mathrm{C}$ below the autoignition temperature. 
Slide 3: Another term which needs definition is "concentration" which is used in the test report in two slightly different contexts. In one case, the concentration of a specific gas that is evolved into the exposure chamber can be measured with laboratory instruments in parts per million (ppm), for example, carbon monoxide. On the other hand, it is very difficult to measure the concentration in ppm of a mixture of unknown combustion products generated when a material sample is decomposed. Therefore, the concentration of mixed combustion products is defined as the mass loading of the material that is placed into the cup furnace divided by the exposure chamber volume. This concentration is expressed in milligrams per liter (mg/l). "Concentrationresponse" is a graphic representation of the concentrations (ppm or $\mathrm{mg} / \mathrm{l}$ ) required to produce a specified response in a percentage of animals. In this test method, the blological response or endpoint which is measured is animal death within the 30 minute exposure and/or within a 14 day postexposure observation period. From such a concentration-response curve (an example will be shown later) an $L_{50}$ value can be estimated. An "LC 50 " is defined as the concentration which is necessary to produce death in $50 \%$ of the test animals exposed for 30 minutes and observed for 14 days. The LC 50 values presented in the toxicity test method report were statistically calculated by the method of Litchfield and Wilcoxon (J. Pharmacol. and Expt. Therapeut. 96:99-113, 1949).

Slide 4 shows a plcture of the NBS exposure chamber. The test method Involves three components: a combustion system, a chemical analytical system, and an animal exposure system. The combustion system is located below the left side of the exposure chamber and consists of a cup furnace (slide 5) in which the test material is decomposed at a preset temperature, $25^{\circ} \mathrm{C}$ above or below the predetermined auto-ignition temperature. The combustion products are generated directly in the exposure chamber. Some of the smoke is pumped from the exposure chamber and analyzed continuously for carbon monoxide, carbon dioxide, and oxygen during the 30 minute exposure. All smoke removed for chemical analysis is returned to the exposure chamber, i.e., the system is kept static.

This test is designed to assess the acute toxicity of combustion products. In order not to confound the results with the physlological effects of heat stress or oxygen deprivation on the animals, the test 
method specifies that the average temperature at the nose level of the animals during the exposure should not exceed $40^{\circ} \mathrm{C}$. Temperatures at the nose position of the animals as well as in the cup furnace are monitored continuously during the exposure. Also the test method specifies that the average oxygen levels throughout this exposure should not fall below $16 \%$.

The exposure chamber is a 200 liter rectangular box and the animals, six rats per experiment, are exposed in a head-only mode, i.e., only the heads of the animals are exposed to the combustion products. The exposure lasts for 30 minutes after which the animals are kept for a 14 day postexposure observation period. Blood is sampled from two of the six animals and analyzed for carboxyhemoglobin. Carboxyhemoglobin is the molecule that is formed within the blood when animals inhale carbon monoxide. As the carboxyhemoglobin levels increase, the oxygen that is usually bound to the hemoglobin is now displaced. In other words, when the blood becomes highly saturated with carbon monoxide, the carboxyhemoglobin levels increase, the oxyhemoglobin levels decrease, and the antmals become starved for oxygen.

This test method also includes an optional 10 minute exposure to a mass loading of 30 milligrams per liter. The 10 minute exposure is intended primarily to allow product researchers and material manufacturers to distinguish those materials which rapidly produce lethal concentrations of toxicants. The response of the animal to the toxic insult absorbed during the test may occur during the 14 day post-exposure period.

Slide 5 is a picture of the cup furnace consisting of a removable quartz beaker surrounded by a heating element which is encased in insulation. A thermocouple is placed in a well within the quartz beaker to monftor the temperature throughout the exposure.

Most of the limitations of this test method concern the combustion system (slide 6). One of the limitations is the quartz beaker size which limits the quantity of material, especially low density materials, that can be accommodated by this combustion system. NBS did experiment with a larger size cup furnace which was an improvement, but 1 st 111 does not permit large quantities to be tested. In addition, the cup furnace does not allow 
for the continuous measurement of material mass loss throughout the experiments. In our present system we weigh the quartz beaker plus the material before and after the exposure to determine how much material was decomposed during the 30 minute exposure. Also, the effect of sample orientation is not addressed by this test method. A material is literally dropped into the cup furnace and falls whichever way it falls. Composite materials referred to as "assemblages of nonuniform structure" in the test method report have not been evaluated by this combustion system. And finally, there are two degradation modes, flaming and nonflaming; we do not look at all possible fire conditions.

As mentioned earlier, materials are examined above and below their auto-ignition temperature. It would make the test extremely costly if every material had to be tested at every temperature. The results of NBS and the laboratories that participated in the interlaboratory evaluation of the test method and data in the literature all show that the most toxic conditions are generated at temperatures close to each material's auto-ignition temperature. As the temperature rises and approaches the auto-ignition temperature, more and more of the material is degraded and more toxic products are produced. And, of course, in the flaming mode, the higher the temperature, the more complete the combustion, the ultimate result of which is the production of only carbon dioxide and water. If materials are examined under their most toxic conditions, then we avoid false negatives, i.e., the situation where a material may produce even more toxic products under conditions that have not been tested. The material modacrylic was decomposed at different temperatures in both the flaming and nonflaming mode. The results (slide 7) clearly show that as the temperature increases in the nonflaming mode, the $\mathrm{LC}_{50}$ decreases, i.e., less material is needed to cause the animals to die. The lower the $\mathrm{LC}_{50}$ value, the more toxic the situation is.

During the interlaboratory evaluation of the toxicity test method, seven laboratories examined a total of 12 materials including both synthetic and natural materials. Not all the laboratories looked at all 12 materials. The natural materials were Douglas fir, red oak and wool; the others were all synthetic. The material abbreviations shown (in slide 8) are used throughout 
the toxicity test method report. The test results that are provided here and in the report pertain to the particular samples of these materials that were used for this study and are not necessarily representative of the generic class of materials that would fall under this particular name.

Slide 9 shows a typical concentration-response curve from which the $\mathrm{LC}_{50}$ or the $\mathrm{EC}_{50}$ (the concentration necessary to incapacitate $50 \%$ of the animals) can be estimated. The $Y$ axis gives the percent response of the animals and the $\mathrm{X}$ axis provides the concentration of the combustion products as defined by the mass loading of material per unit chamber volume. Each point (on this graph) is a single test consisting of six animals which were exposed to one mass loading. From such data, we can now statistically calculate the $\mathrm{LC}_{50}$ or the $\mathrm{EC}_{50^{\circ}}$. During the development of the test method, different biological endpoints were examined. The $\mathrm{LC}_{50}$ was calculated for the 30 minute exposure itself as well as for the 30 minute exposure plus 14 day post-exposure observation period. In addition, the $\mathrm{EC}_{50}$ for 30 minutes and the times-to-incapacitation were also determined.

Slide 10 shows NBS results for flaming combustion. The $\mathrm{EC}_{50}$, the concentration that caused $50 \%$ of the animals to become incapacitated in the 30 minute exposure; the $\mathrm{LC}_{50}$, the concentration that caused death in $50 \%$ of the rats in the 30 minutes and 14 days; and the $\mathrm{LC}_{50}$, the concentration that caused lethality in $50 \%$ of the rats during the 30 minute exposure itself, are plotted against the mass loading divided by chamber volume for all 12 materials. In classical toxicology, one material is considered significantly more toxic than another material if the toxic concentrations differ by an order of magnitude. However, in this series of experiments, only one material (PTFE) turned out to be orders of magnitude more toxic than the other materials tested. * These data also show that regardless of the endpoint $\left(\mathrm{EC}_{50}\right.$ or $\left.\mathrm{LC}_{50}\right)$ examined, the relative toxicities of the materials do not significantly change except for PTFE. With this particular material, a11 deaths occurred postexposure. No incapacitation or death was observed during the thirty minute exposure. A hundred fold increase in the mass loading of this material still

\footnotetext{
Experiments carried out in another laboratory subsequent to the publication of this report indicate that the conditions of thermal decomposition used in the NBS test--i.e., the absense of flame from other combustibles--may not be appropriate to the toxicity testing of PTFE (the only polymeric material which does not contain hydrogen). Testing in a hydrocarbon flame indicated the $\mathrm{LC}_{50}$ to be slightly less than but of the same order of magnitude as for the other materials tested.
} 
did not produce any incapacitation or death within the 30 minute exposure. Our conclusion from this information is that the biological endpoint that provides the most information as to the toxicity of a material is the $\mathrm{LC}_{50}$ for 30 minutes and 14 days which includes the post-exposure results.

The toxicity test method also includes an optional 10 minute test which is primarily designed to enable product researchers and material manufacturers to distinguish those materials that rapidly produce effective concentrations of toxicants. Slide 11 shows the results of this test performed on two materials - PVC and PVC-ZnFeCN under both flaming and non-flaming conditions. These materials have the same chemical formulation except that the PVC-ZnFeCN has in addition zinc ferrocyanide, a smoke suppressant. The 10 minute results can be compared to the $\mathrm{LC}_{50}$ values for 30 minutes and 14 days. Using orders of magnitude as the criterion to determine whether one material is significantly more toxic than another material, these two materials can not be distinguished by the $\mathrm{LC}_{50}$ results. However, when the animals were briefly exposed for 10 minutes to $30 \mathrm{mg} / \ell$ and observed for 14 days, the PVC-ZnFeCN killed $100 \%$ of the animals in all cases in both the flaming mode and the nonflaming mode. PVC, however, produced only one animal death in three experiments in the flaming mode and no deaths in the non-flaming mode. Therefore, the 10 minute test provides a means of distinguishing between materials which rapidly produce toxicants and those that do not.

As an example of the importance of following the toxicity test method closely, slide 12 shows some of the research performed at NBS to determine the best time to take blood samples. The test method specifies that the blood samples for carboxyhemoglobin measurements should be taken either at the end of the exposure or within 5 minutes following the end of the exposure. Slide 12 shows the percent of hemoglobin saturated either with oxygen or carbon monoxide plotted against time. The time axis is divided into the time of the exposure ( $30 \mathrm{~min}$. ) and a long post-exposure period during which blood samples were taken. These animals were exposed to an average concentration of 4100 ppm of carbon monoxide for 30 minutes and no animals died. During the exposure, there is a rapid increase in carboxyhemoglobin to a level of $84 \%$ and simultaneously, there is a rapid decrease in the oxyhemoglobin. Immediately upon removal of these animals from the chamber, the carboxyhemoglobin levels start to drop. The decrease in percent carboxyhemoglobin is so rapid that if blood samples are taken long after the exposure is over, the levels observed will not be related to that which the animals actually experienced during the 
exposure itself. Therefore, we do recommend arterial cannulation of the animals. This procedure allows blood sampling without removing the animals from the exposure conditions. However, if cannulations are not performed, then rapid sampling is important for reliable results. The longer the delay, the more significant the error.

Post-exposure death was not an isolated phenomenon. The combustion products of many materials produced both within-exposure deaths and postexposure deaths at the concentrations tested. A few materials produced only within-exposure death and a few materials produced only post-exposure death. Therefore, in the assessment of the toxicity of the combustion products of materials, it is important to examine both within-exposure and post-exposure deaths. The test method specifies that the animals be observed for 14 days, a time period during which the various materials caused deaths (slide 14).

What about the reproducibility of this test method? As mentioned earlier, an interlaboratory evaluation was conducted. The $\mathrm{LC}_{50}$ results for 30 minutes and 14 days for Douglas fir as determined by seven laboratories are shown in slide 15. NBS is 1isted here at NBSa and NBSb because NBS tested both a $360 \mathrm{ml}$ furnace and $950 \mathrm{ml}$ furnace. Douglas fir is the appropriate material to examine for reproducibility across laboratories as all of the laboratories tested Douglas fir and only a few laboratories tested each of the other materials. The Douglas fir results show good reproducibility between laboratories under both non-flaming and flaming conditions. It is important to note that this was an interlaboratory evaluation; it was not a round-robin in which each laboratory was told exactly what concentrations to test and how to exactly replicate experimental conditions. There were variations both in how experiments were run and the methodology used. However, slide 15 still shows good reproducibility between laboratories. Data for other materials can be found in Table 17 of the test method report (NBSIR 82-2532). NBS is planning to publish a report on the interlaboratory evaluation of this other data soon.

In conclusion, this presentation has described very briefly the toxicity test method that was developed here at the National Bureau of Standards and discussed its use and its limitations. The Center for Fire Research is planning future work to correct these limitations and Dr. Fowell will be discussing our future research plan after the coffee break. Thank you. 

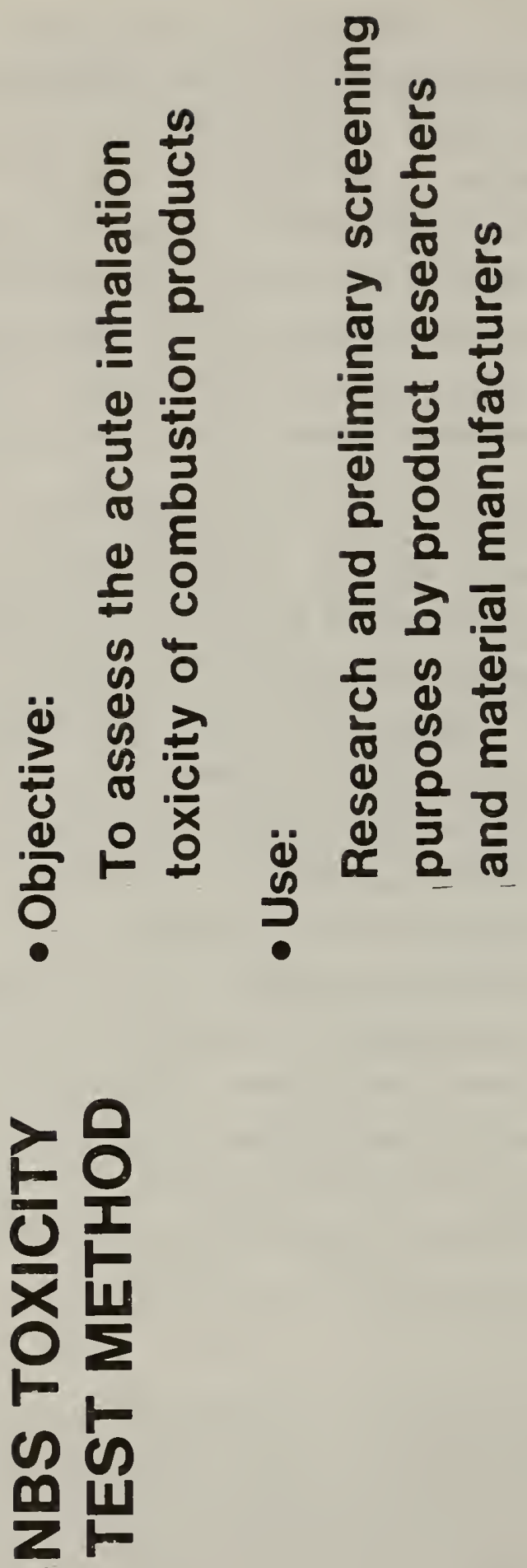

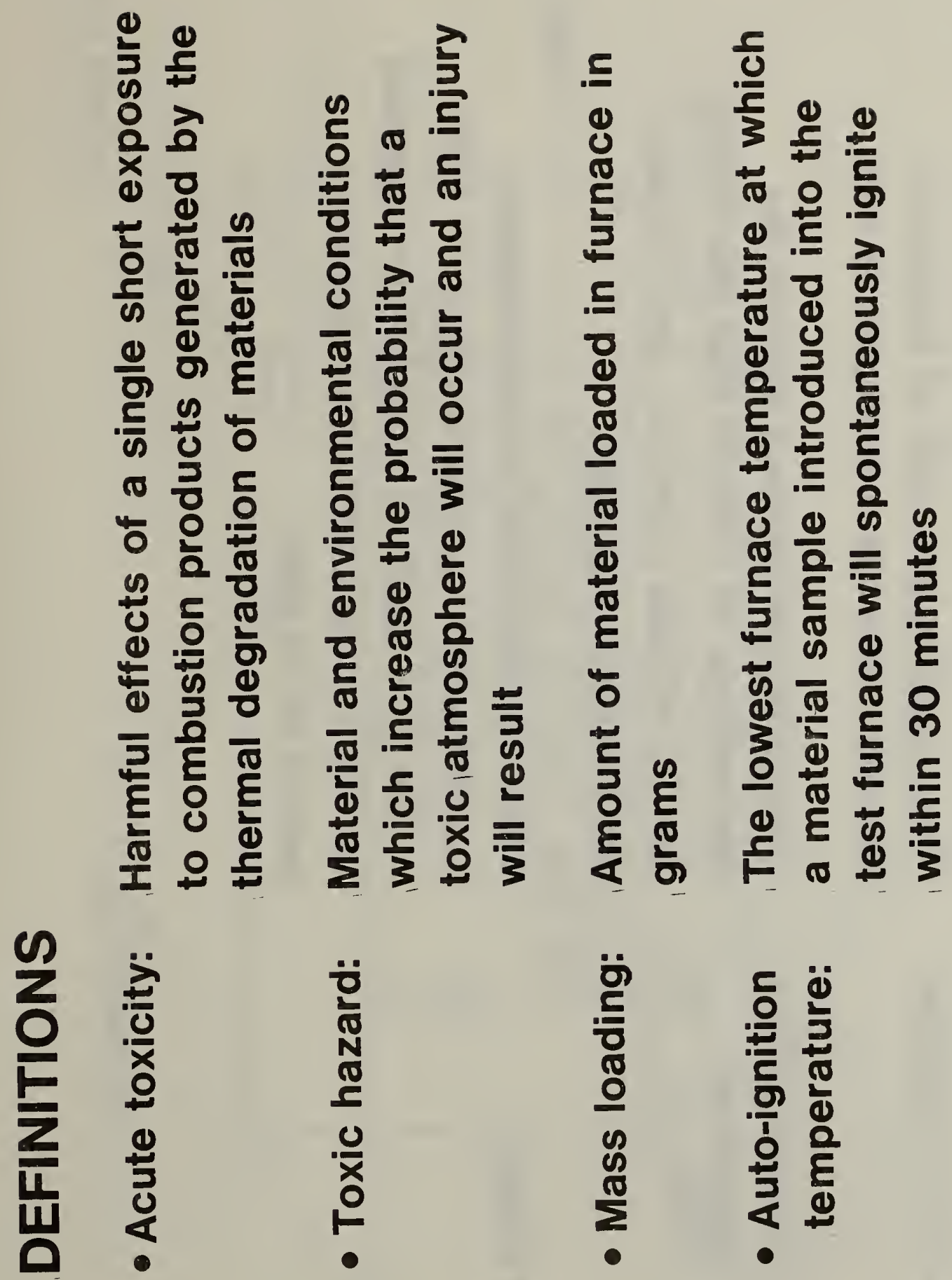


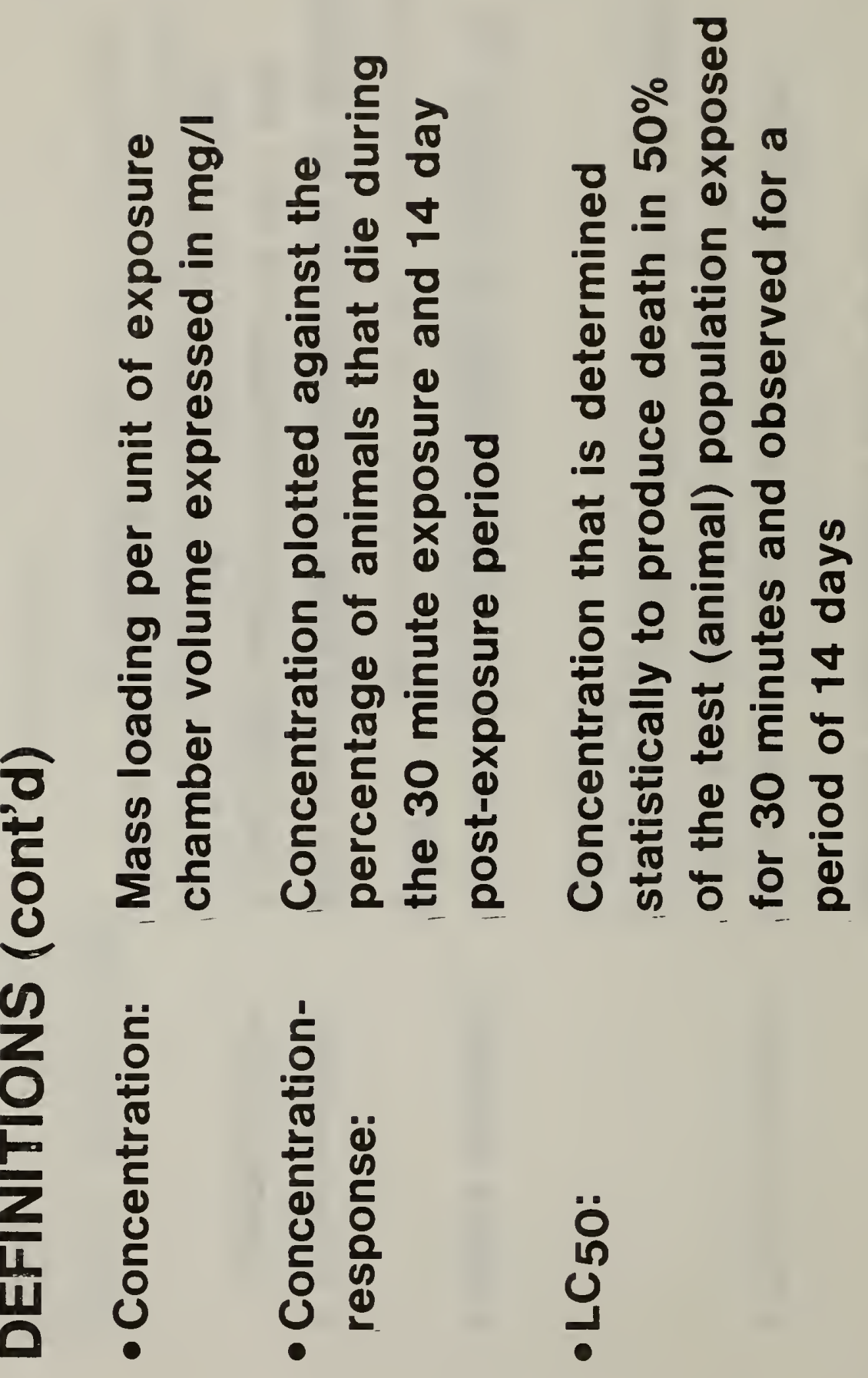




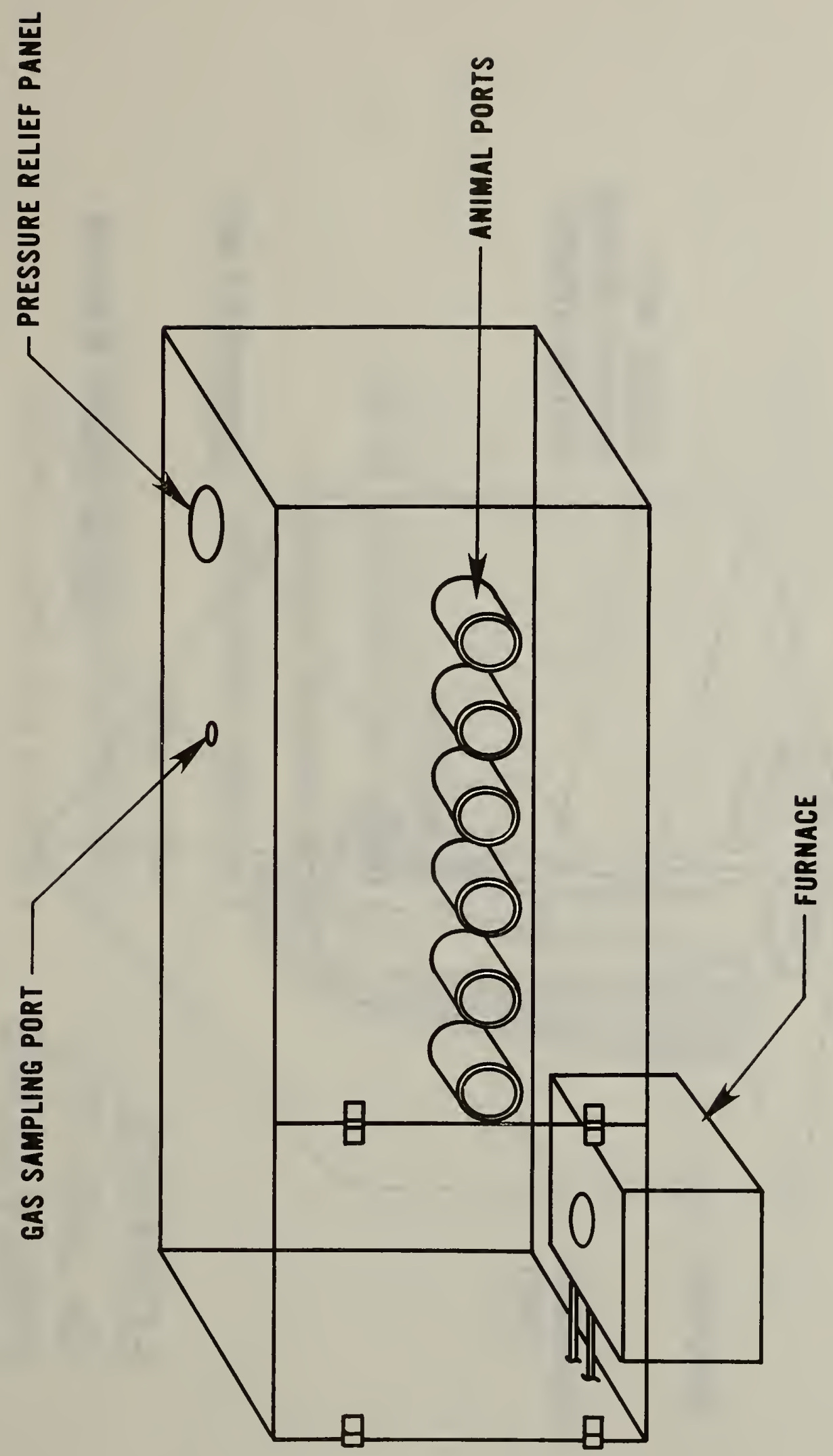




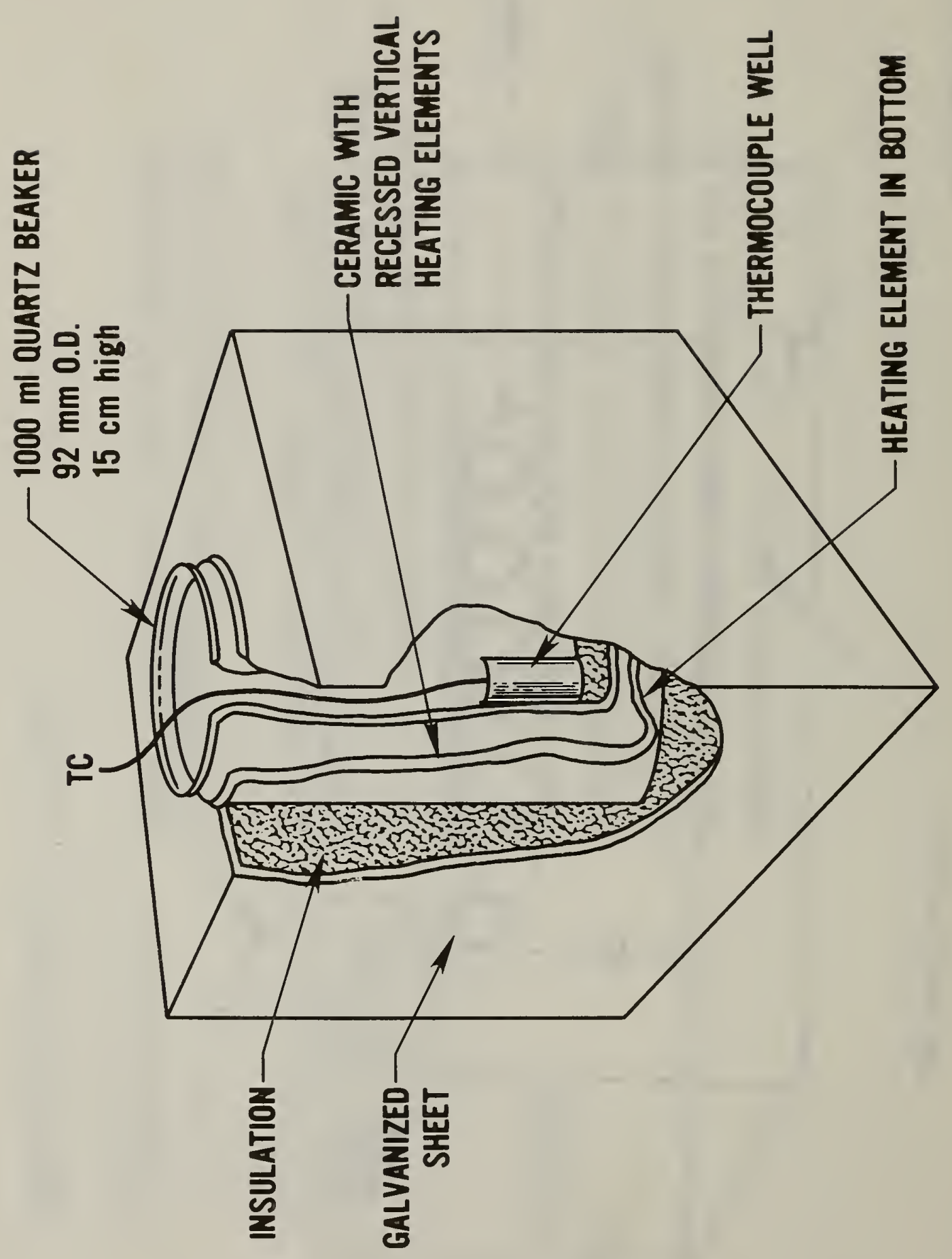



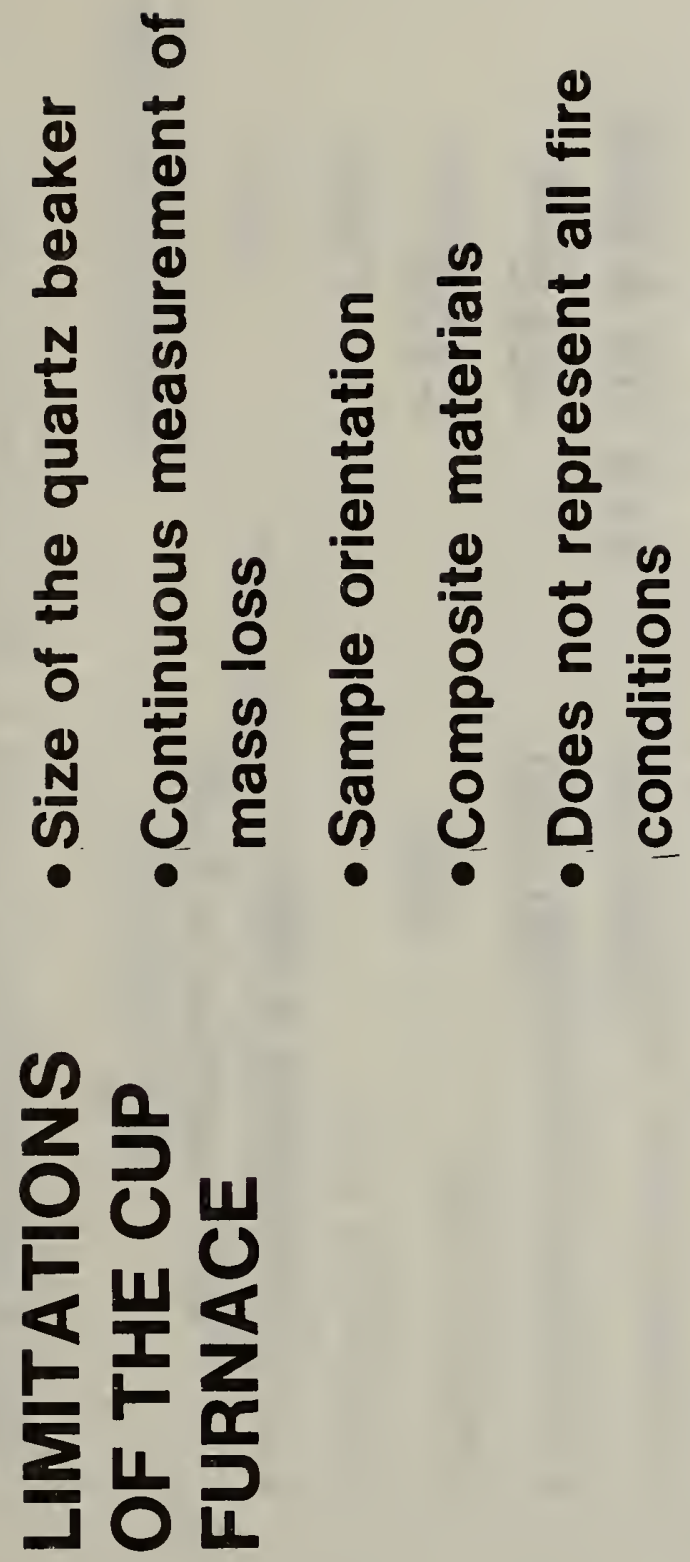


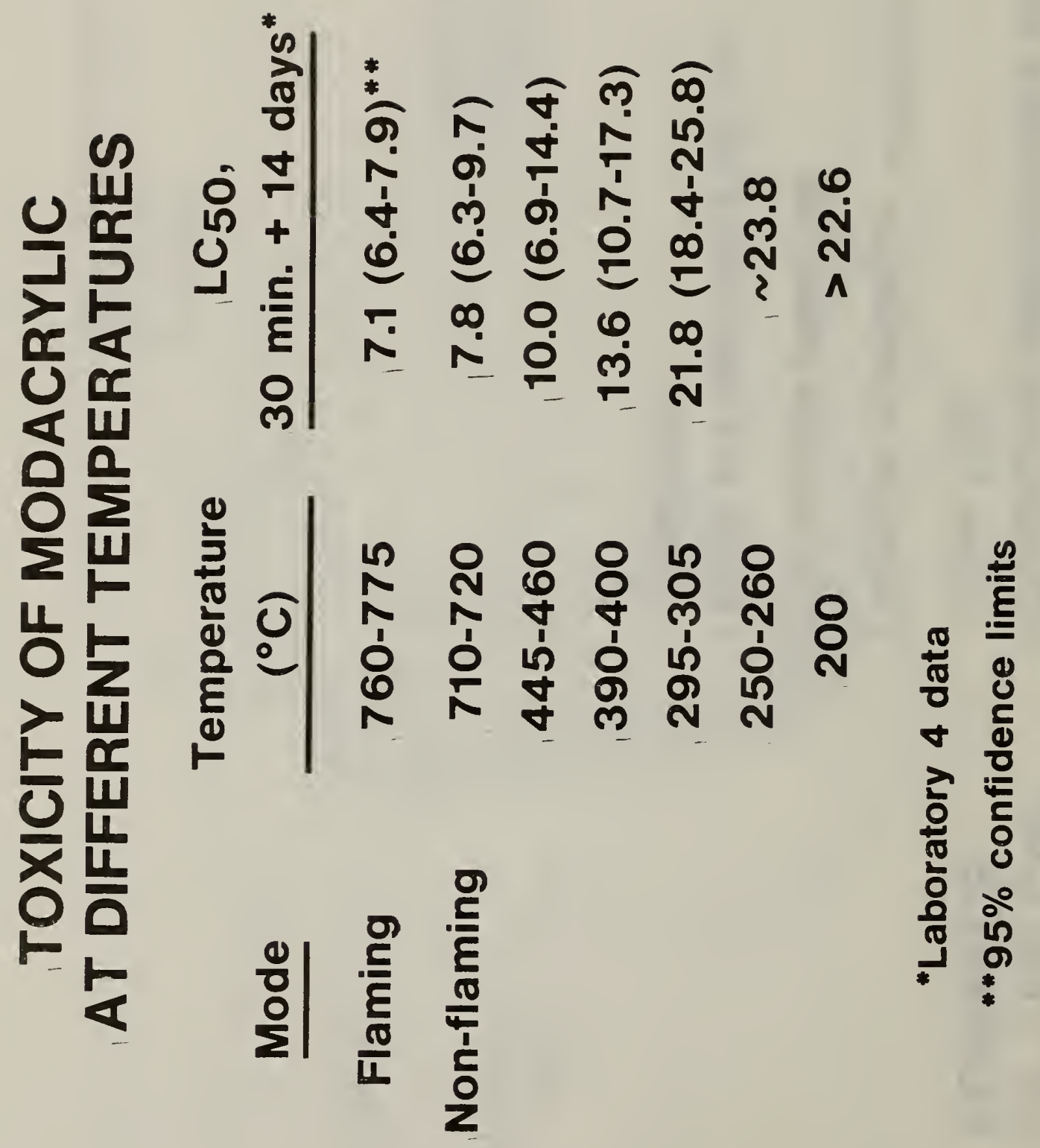




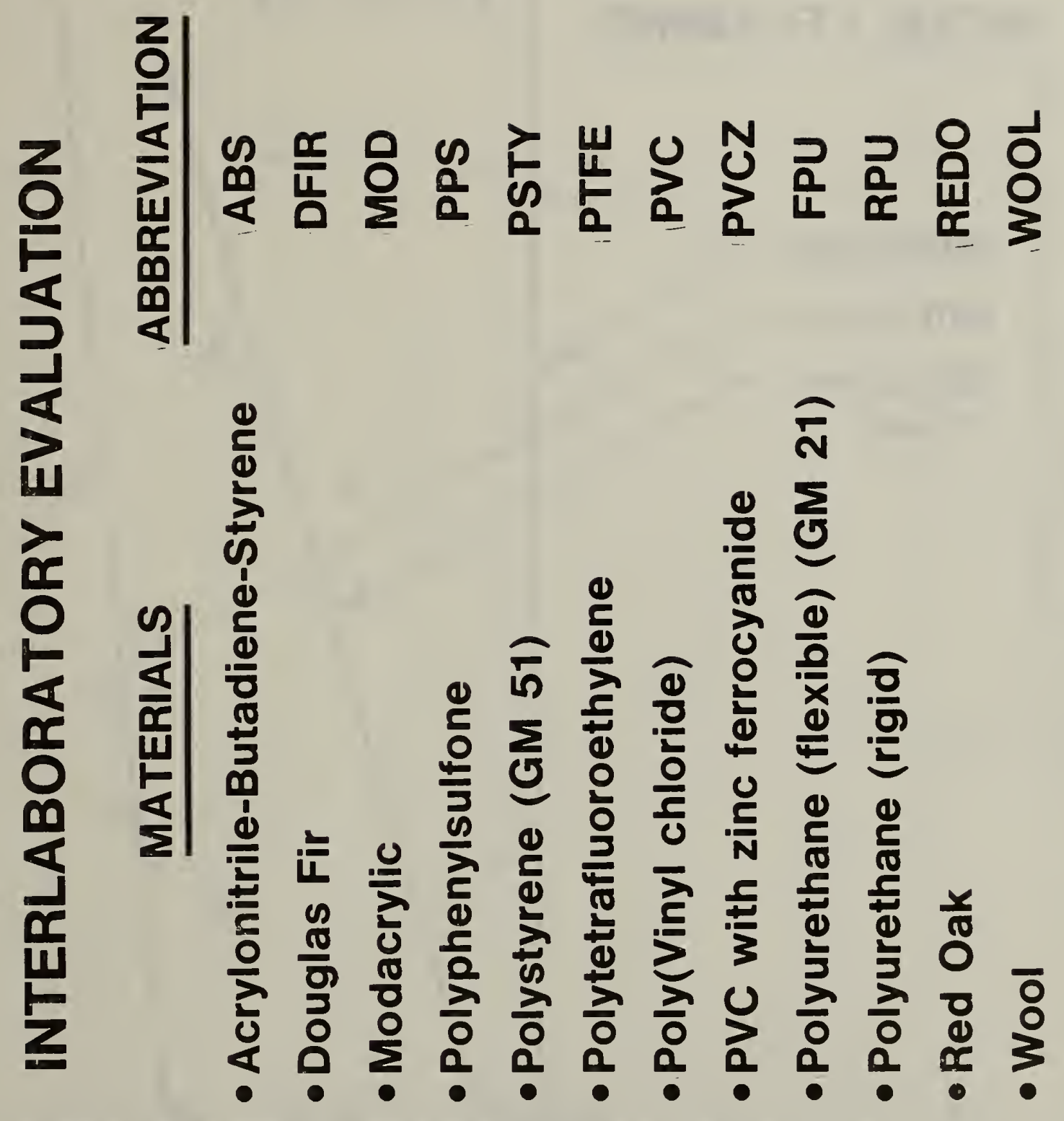




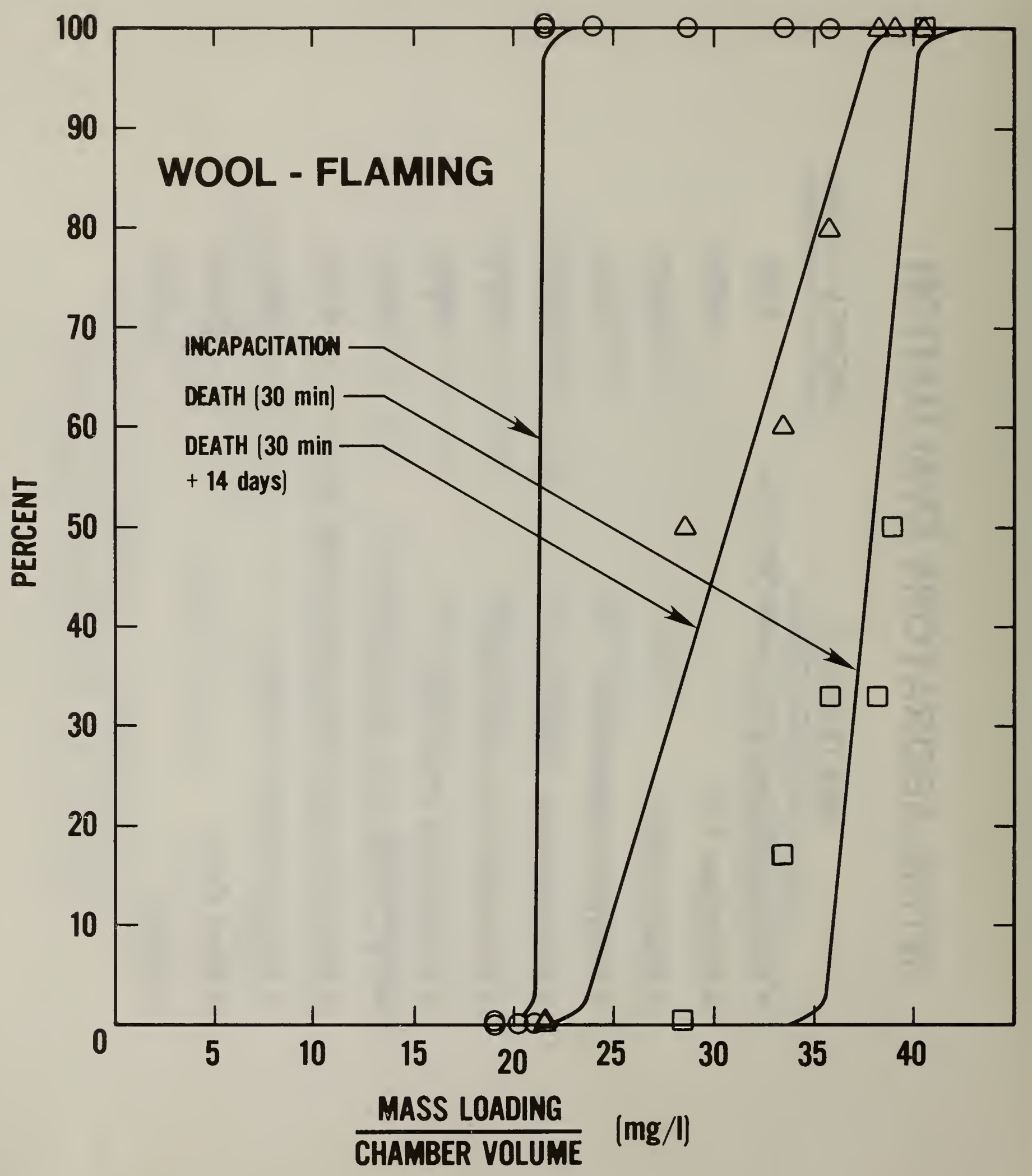




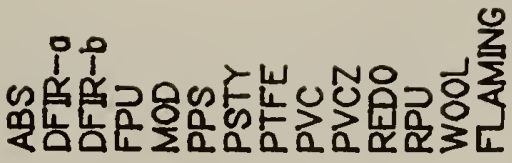

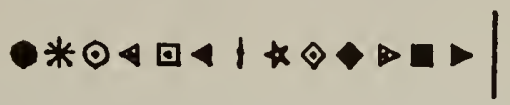

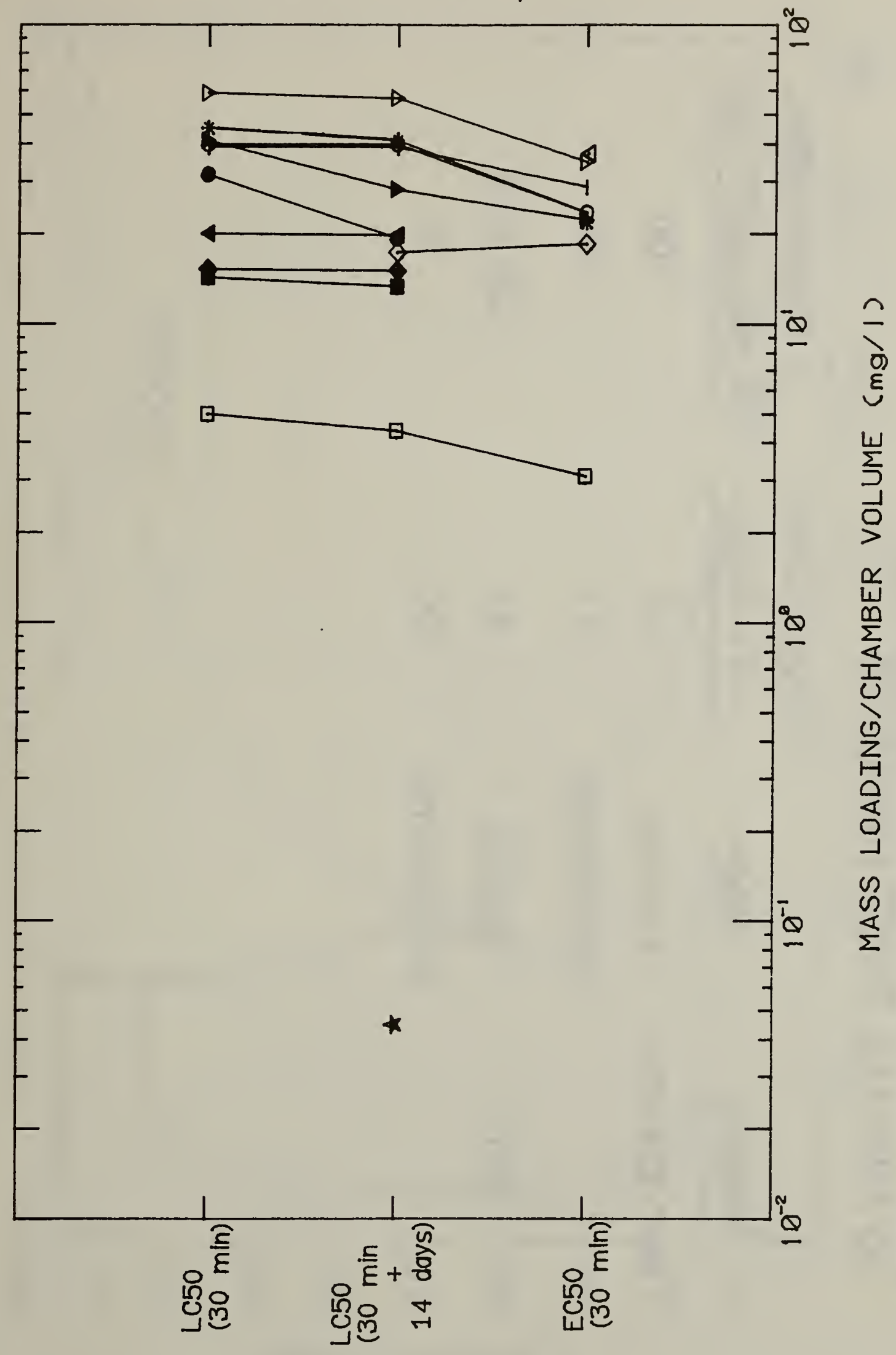




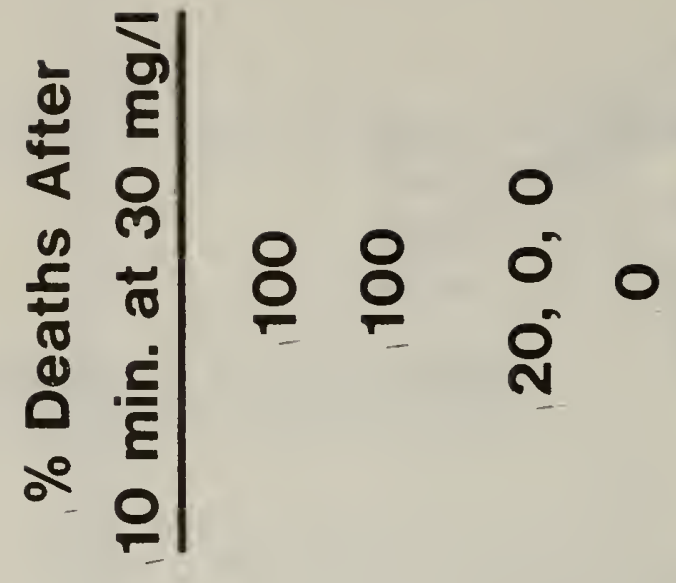

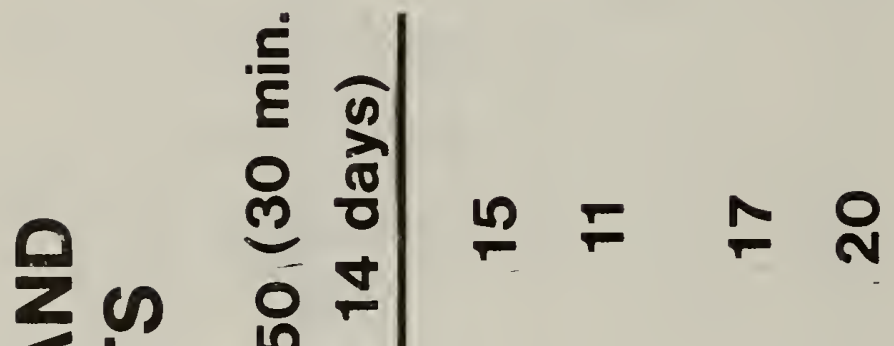

号

एक

崖

岁战

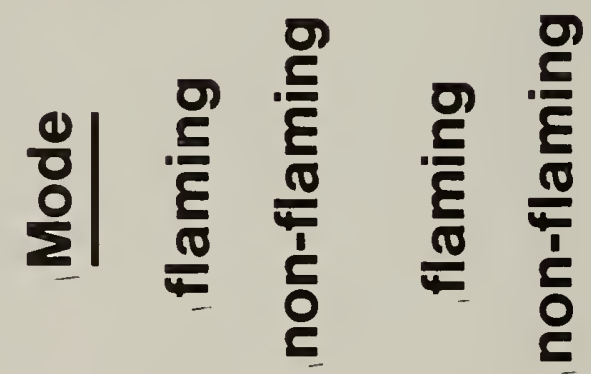

은

क W

또

क)

$\frac{1}{2}$ 


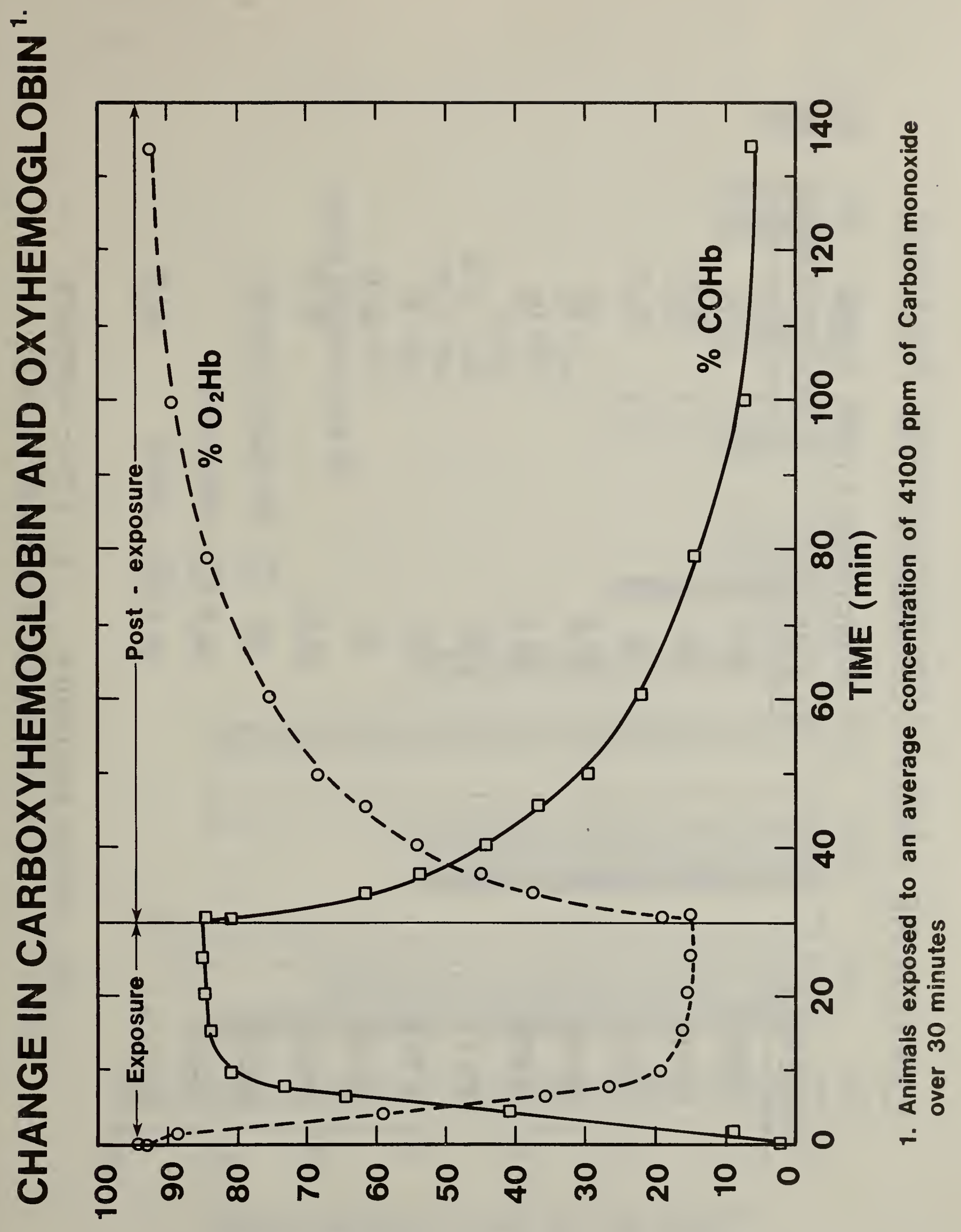

Sヨกาษ^ 000าg \% 


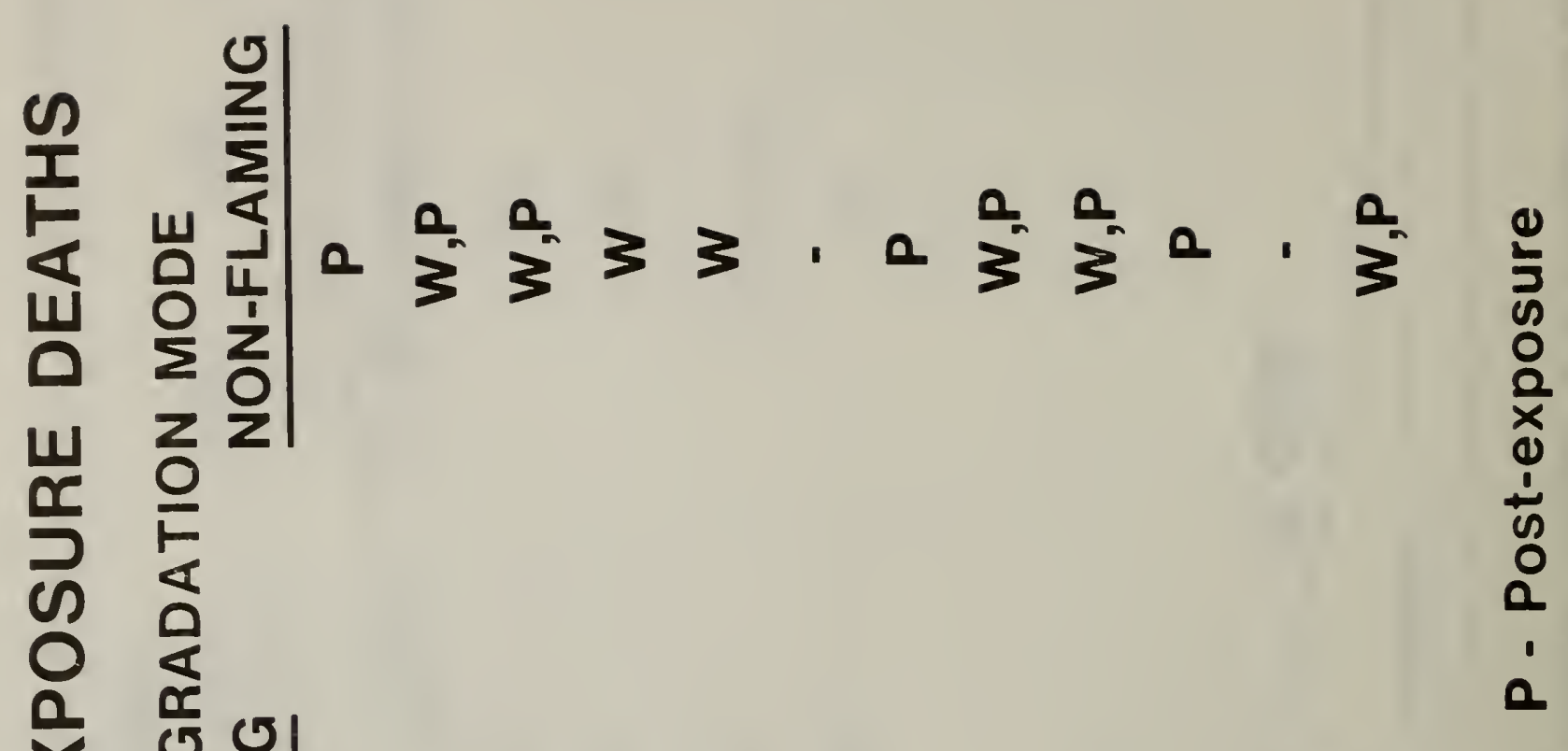

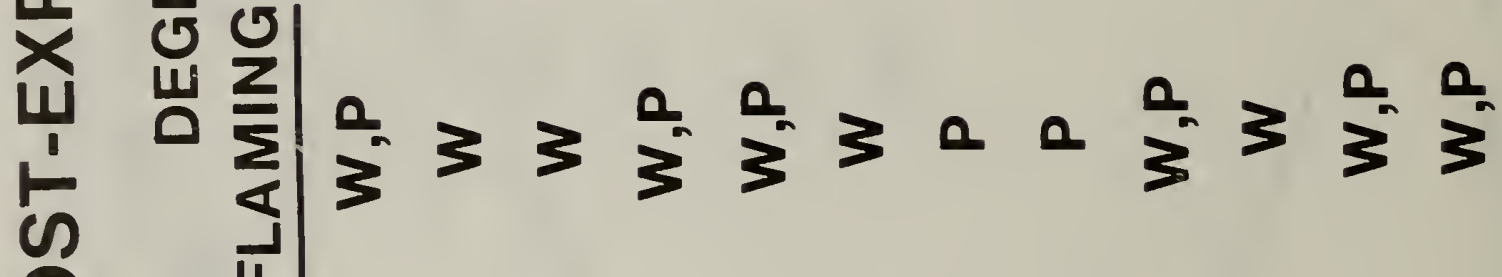

足

U

产

o

$\frac{\vec{s}}{\alpha}$

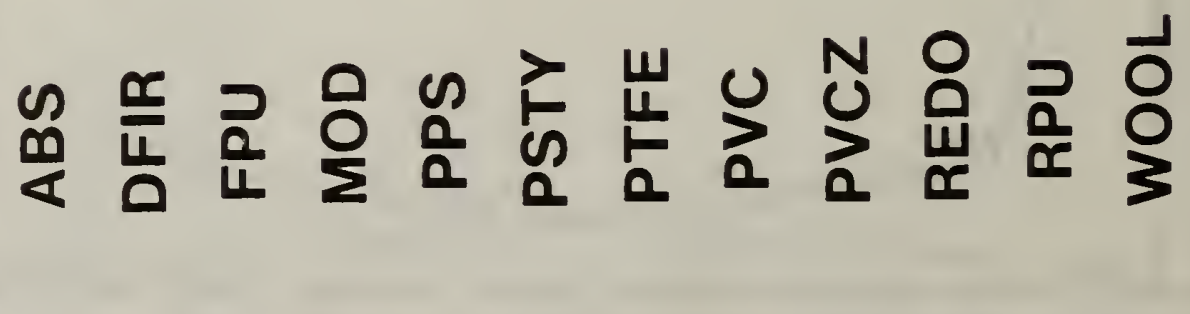




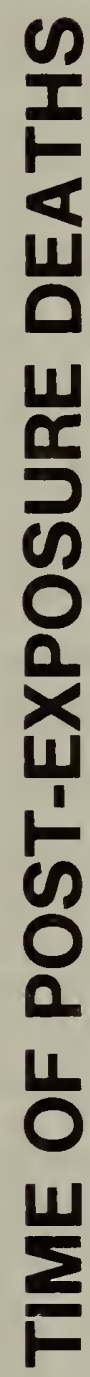

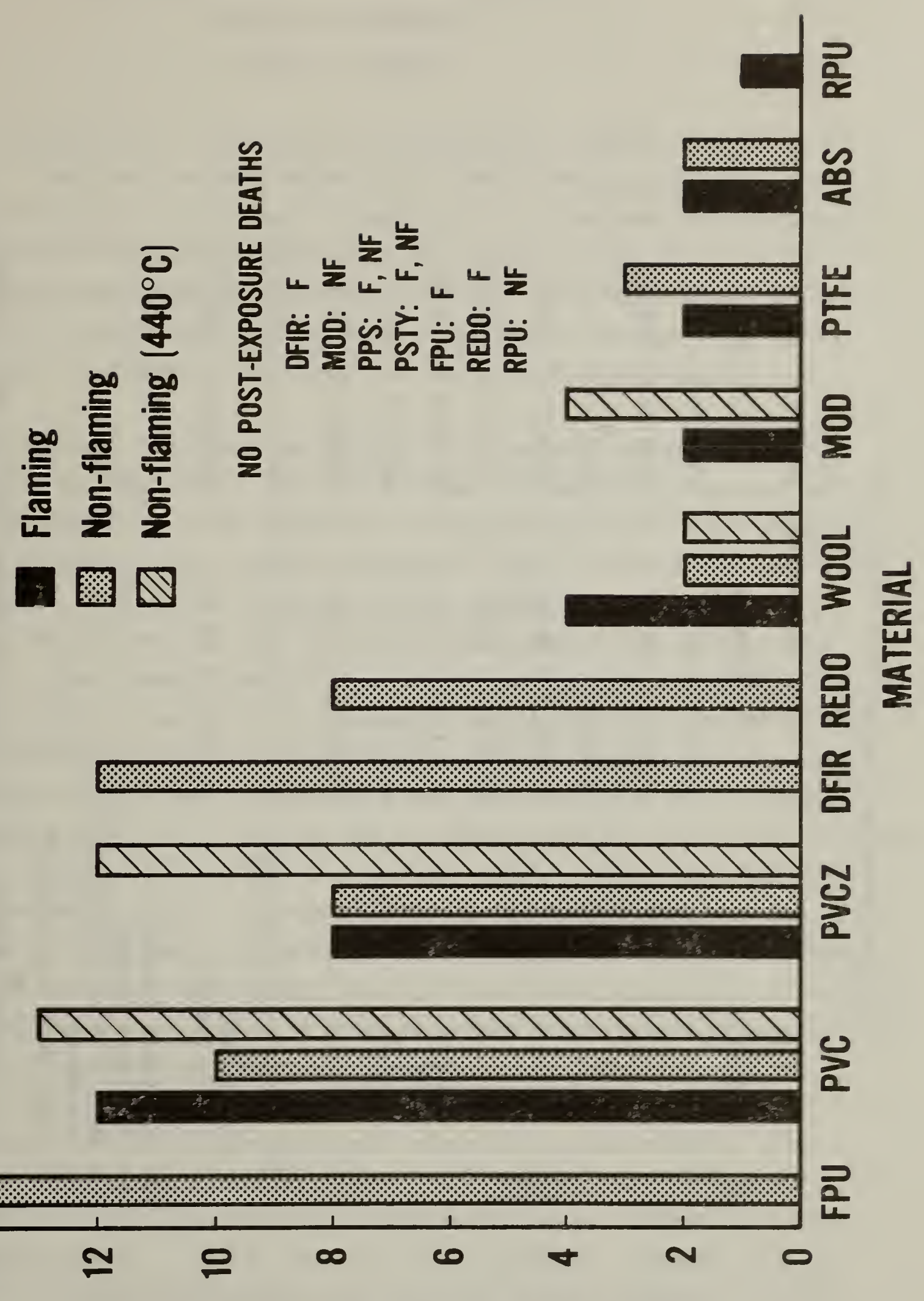

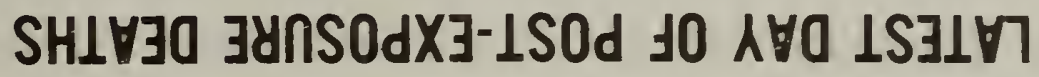




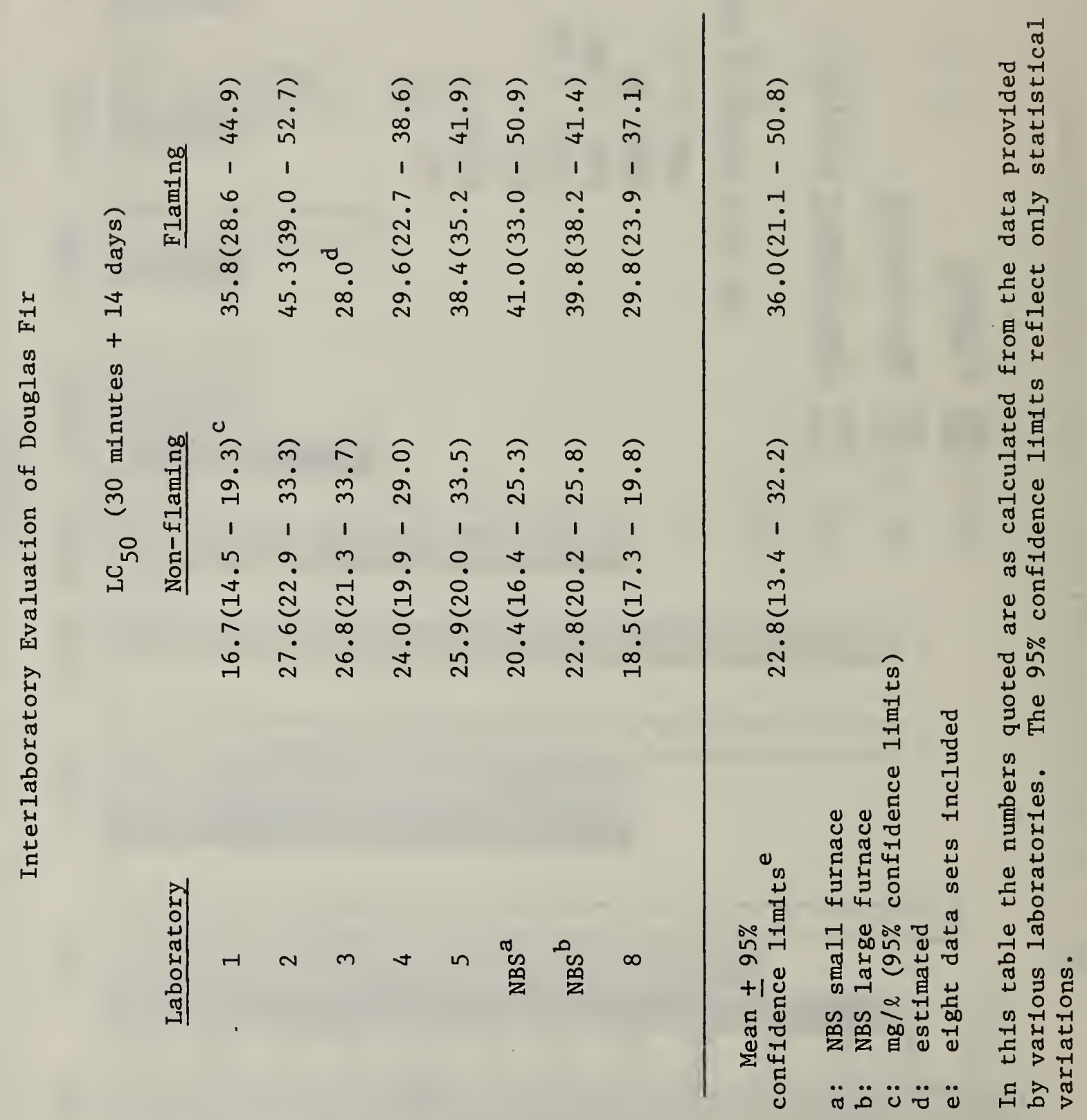




\section{Hazard Assessment--Review of Research in \\ Progress and Planned \\ Andrew J. Fowell}

My purpose today is to describe the additional research planned at NBS relating to the toxicity test method and to toxic hazard assessment. First, I'll discuss some of the current limitations of the test method particularly those on which we intend to concentrate our effort. Then, I'll describe various approaches to hazard assessment, and give an example of the kind of output that we expect from some of the more elaborate techniques. Finally, I'11 outline our plans for work in hazard assessment methodology.

(See slide 1). Several test methods for measuring combustion product toxicity are now available. They can provide information for research and product development but they should not be incorporated directly into building codes and standards, for a number of reasons. There is very little available information on toxicity of materials obtained using either the NBS or the other test methods and the ways to use this information have not yet been developed. Also, some technical issues need to be resolved including how to deal with composite assemblies of materials and material orientation. At NBS we are focusing on two areas: the further refinement of the test method to address some of the current limitations; and the development of a framework for combining toxicity information with the other information so that regulators or decision makers can make better decisions on fire safety. This other information--which includes the material's own fire properties, use data, and statistics on fires--may be considered "application information". The combination of "material performance" data with "application information" comprise toxic hazard assessment. This is shown in dashed lines because to date we lack procedures for conducting such an assessment.

What are the current limitations of the toxicity test method? (See slide 2). Barbara Levin mentioned these. The time to reach untenable conditions is a key factor in addressing hazard. So, an indication of the rates of generation of combustion products is important. Therefore, some continuous measure of mass loss of the material would be a good indicator. Few materials are ever used on their own; they are usually used in 
combination with other materials or formed into assemblages of materials. The current test method has not really addressed composite materials. To test these materials a different combustion system will probably be needed, and it is likely to be some form of radiant system. The size of the present cup furnace is a limiting factor for low density materials. In burning materials, oxygen is a critical factor in determining the products of combustion, particularly carbon monoxide. Therefore, some measure or control of the oxygen in the combustion system should be included. The exposure conditions, the ventilation conditions and the material orientation all are factors that contribute the combustion products and therefore our combustion systems must take this into account.

We in the U.S. are not the only people working on combustion toxicity. Efforts are underway in Japan, Germany, Canada, England, France, Sweden, and many other countries. The Japanese are focusing on the correlation between small scale and large scale tests, which bears on the subject of verification. The Japanese also are attempting to simulate real fire conditions. The Canadians concentrate more on analytical techniques rather than exposing animals. Although the English researchers have used primates in their tests, they concentrate mostly in the analytical area. We in the U.S. have set up collaborations with both Japan and Canada to exchange information and look at the correlation between our various test methods and the results of using the various techniques.

What are we planning to do about the limitations of the test method mentioned? (See slide 3). The first effort will be to better control combustion by redesigning combustion systems. We have done some initial work on radiant heating systems. Our work in full-scale testing and modeling of fires will give us a lead on the design requirements of that combustion system. At the same time as refining the combustion system, we may modify the animal exposure system if necessary to control the temperature at the noses of the animals, and the oxygen level to make sure that the animals aren't too affected by high gas temperatures or oxygen depletion.

Once modifications have been made to the test equipment we will correlate any new measurements with the data we have from the old system. 
Following the modifications to the equipment, we plan to examine the composite material and material orientation questions. Another problem we see with toxicity testing is cost. It would be very nice to explore every parameter in every direction. This is impractical. Some time can well be spent selecting appropriate standard test conditions.

As we have said a number of times today, when considering the suitability of a material for a particular use the results of small scale toxicity tests should be considered along with information on its other fire properties. In fact, in the test method itself we list a number of these properties in the "Significance and Use" section of the report, (section 2.2.2).

Combining this fire property information with application information leads to hazard assessment. Various approaches that either have or can be used for hazard assessment are listed on slide 4. I'm going to concentrate on the last two items. They are the more quantitative approaches. But first, let's look at chemical analysis techniques. Since they don't rely on animal testing, some unsuspected or unknown toxicants can be missed. The French code requires* the use of a chemical analysis technique in the regulation of building materials in public buildings. They consider two gases, hydrogen chloride and hydrogen cyanide. A limit is placed on the maximum concentration of these gases that could possibly be generated by the chlorine and nitrogen in the furnishings of the room and the wall covering materials. There are various weighting factors incorporated into the calculations when floors and walls are considered. The second approach on the list, subjective assessment, is really the approach that is being used today. It's a way of comparing the various fire properties of different materials with those of some standard material or with some other familiar material.

Of the the two more quantitative approaches to hazard assessment the last one, mathematical modeling, is the more sophisticated or elaborate. It combines mathematical models of fire growth and fire spread with the capabilities of computers to predict the time to reach untenable conditions

*Since this presentation, it has come to our attention that this analysis technique is not in regular use in France. 
within various parts of the building under various fire scenarios. But first, let's look at each of the two quantitative approaches.

The information that we get from the test method, the $\mathrm{LC}_{50}$, is the mass loaded in thecombustion system divided by the volume of the chamber which is necessary to cause death in fifty percent of the animals as a result of a 30 minute exposure (slide 5).

If we multiply the $\mathrm{LC}_{50}$ by 30 minutes, it gives us some idea of the lethal dose $\mathrm{D}^{*}$ for the animals. Now consider a compartment containing a burning material. The rate of mass loss of that material is $\dot{\mathrm{m}}_{\mathrm{f}}$. The burning material generates flow into and out of the room through any open doorway or window. The volume flow out of the room $\dot{v}_{0}$ can be calculated from the heat generated by the burning material and the temperature in the room. So we have a concentration of toxicants flowing out of the room, the mass generated divided by the volume flow rate. Multiply that by the time under consideration and we have a dose. So now we have a very crude, very simple way, assuming the material is burning at a steady state, to calculate the time to reach a lethal dose. Now I'd be the first to recognize that for many toxicants the lethal dose itself is dependent on concentration. In fact, in the test method, we recognize this by doing a 10 minute test. But, for the purposes of this crude calculation we' 11 make that assumption. We can elaborate on this technique by adding to the calculation the time for a material to get involved in the fire. The techniques to do this are available and they give us a much better indication of time to reach toxic conditions.

A more elaborate or ideal method of assessing fire hazard is to combine the latest models of both fire growth and fire spread with the capabilities of computers to predict the changing conditions in various parts of a building. (See slide 6). Here I show just two examples of fire growth models. One developed at harvard for single compartments and another one developed by Professor Tanaka in Japan, for multi-room or multi-compartment spread of smoke throughout a building. There are many models and many submodels available. In the first one, the fire growth within a single compartment, the usual approach is a zone model where the compartment is divided into a number of zones, such as the upper smoke layer, the lower cooler layer, and the turbulent plume above the fire. (See slide 7). Some of the factors that are considered in developing these various models include the air flow 
Into the room, the mixing of the products of combustion into that inflow air, the escape of the products of combustion, heat transfer to the ceiling and walls, and radiation from the flame and from the upper zone to the floor and to other materials in the room. This particular model is undergoing various stages of modification and parameters are constantly being added or modified. Thus, the model is becoming much more sophisticated.

This next slide (see slide 8 ) is a pictorial representation of the Tanaka model of smoke filling a building. Starting in the upper left corner of the slide, we see a fire on the second level generating smoke which spreads from the room of origin into neighboring compartments and to the upper floors. As we examine the figures down the left hand side and then down the right hand side of the slide we see a progressive filling of the building with smoke. So, through a combination of models like these that we can generate the overall fire hazard or the fire safety picture for a particular building.

In the report on the test method, we list a number of factors that should be combined in assessing overall fire hazard. Some of these are listed on slide 9. These same factors really form the input to these mathematical models. It isn't a complete list but it does show you some of the pieces of information that need to be incorporated into the models to give us a good understanding of the fire growth. The output that is of interest to us at the present time is the time to reach tenability limits. These tenability limits have to do with toxicity, temperature, and visibility. We are examining the literature to determine what values to use for these limits.

An important purpose of modeling is to gain a better understanding of the fire growth process and to reduce the number of repetitive large scale tests that must be done. As a result many subroutines are continually being added to the modeling framework to account for the various components of the fire process. (See slide 10). Modeling capabilities are limited at this time, primarily by lack of data on both individual materials and composite materials. Another limitation is lack of information on the combustion products in underventilated conditions that are different from those of the test methods. This is one of the criticisms that a standard test method usually encounters. One of the problems with the models that are avallable today is they're not necessarily compatible with each other and so we will be working to improve 
model compatibility. As I said, mathematical modeling is continually being improved by the incorporation of other factors. Factors currently being addressed are forced ventilation and wall fires. In most of the models that exist today, the flows within and between the various compartments associated with the fire, are assessed on the basis of the buoyant effects of the fire itself, whereas, in big buildings the heating, air conditioning, and smoke control systems are a major factor. Not only do we need combined models, or models that are compatible with each other, we also need efficient algorithms so that we can process each model conveniently. Another problem that we have encountered is that many of today's models can only be handled by the experts who developed them. So, effort needs to be directed at simplifying and refining the models.

Modeling gives a good overall picture of the fire growth process if you know where the fire starts, but what is the probability that a fire will start in a particular way, or particular location? We need more input on fire scenario probabilities. Fire statistics that are available today can provide some of this information.

These limitations not withstanding current fire and smoke models can provide useful information. For example, we have run two of the models, the two that I mentioned earlier, the Harvard Code and the Tanaka model, in combination with each other for a very simple situation. (See slide 11). The setup we used was a two room building, the room of origin, (a bedroom) and the rest of the house. We considered only one combination fuel package, a bed and two side tables, but with two different sets of materials. In each case, the fire was assumed to start in the middle of the bed. In this hypothetical example, the kind of output we might expect is shown in slide 12 . Tenability limits for temperature and visibility were assumed as follows: lower layer room temperature reaches $100^{\circ} \mathrm{C}$; and the smoke layer reaches $1 \mathrm{~m}$ from the floor. Two toxicity tenability limits were assumed a) for all the products of combustion, $30 \times \mathrm{LC}_{50} \mathrm{mg} / \mathrm{l} \mathrm{min}$; and b) for carbon monoxide, $4500 \mathrm{ppm}$ min. For each of the fuel packages, designated A and B, we calculated the conditions which first made each room untenable. What this particular example turned up was that tenable conditions persisted in both the room of origin and the rest of the building with fuel package $A$. With fuel package $B$, we did run into tenability limits in very short order. 
Visibility happened to be the first one. This occurred in both the room of origin and the rest of the building. The smoke layer came to within one meter of the floor in 4 to 5 minutes. The second limit that was reached was the lower layer temperature in the room of origin reached $100^{\circ} \mathrm{C}$ in 5 or 6 minutes. Lethal levels of toxicants were not reached in neither of these cases which involved relatively small fuel loadings.

What is our overall plan for hazard assessment in the Center for Fire Research? (See slide 13). It includes research, test method development, experimental studies, particularly in the area of extinguishment systems, an extension to our work in fire modeling and what is more important to you in the audience, the development of models that can be used by the people other than those who develop them. The research effort will include studies such as particulate generation, particulate coagulation, smoldering fires and the combined effects of various toxicants. Work on the development and refinement of test methods will include the rate of generation of combustion products, the rate of heat release, flame spread and refinements to combustion toxicity testing. Not all fires continue unchecked. Fire control systems are effective. So we plan to study the response and effectiveness of extinguishment systems and the effectiveness and field testing of smoke control systems. I have already mentioned that our fire growth modeling will be developed further, particularly the single compartment model where we will address wall fires, forced ventilation, incorporate extinction effects and the use of layered materials on the walls. The multi-room smoke model will be extended to improve prediction of the lower layer temperatures in the various parts of the building, and to handle mixing of the upper and lower layers, scrubbing of combustion products as they flow around the building, and the effectiveness of smoke control systems. That's an ambitious package. It will take quite a long time before all that is complete. However, we intend to develop usable interim models and information for fire hazard assessment. (See slide 14). Some of the more useful techniques that will come out of this program will be cost and loss models, and building egress models. In addition to those tools we'11 be developing or gathering basic data such as various fire scenario probabilities, tenability limits, fire properties of the individual materials and assemblies of materials. 
In summary, what I've covered today is the work we are planning on the test method itself, some approaches to hazard assessment and an outline of our program for developing useful tools for hazard assessment. 


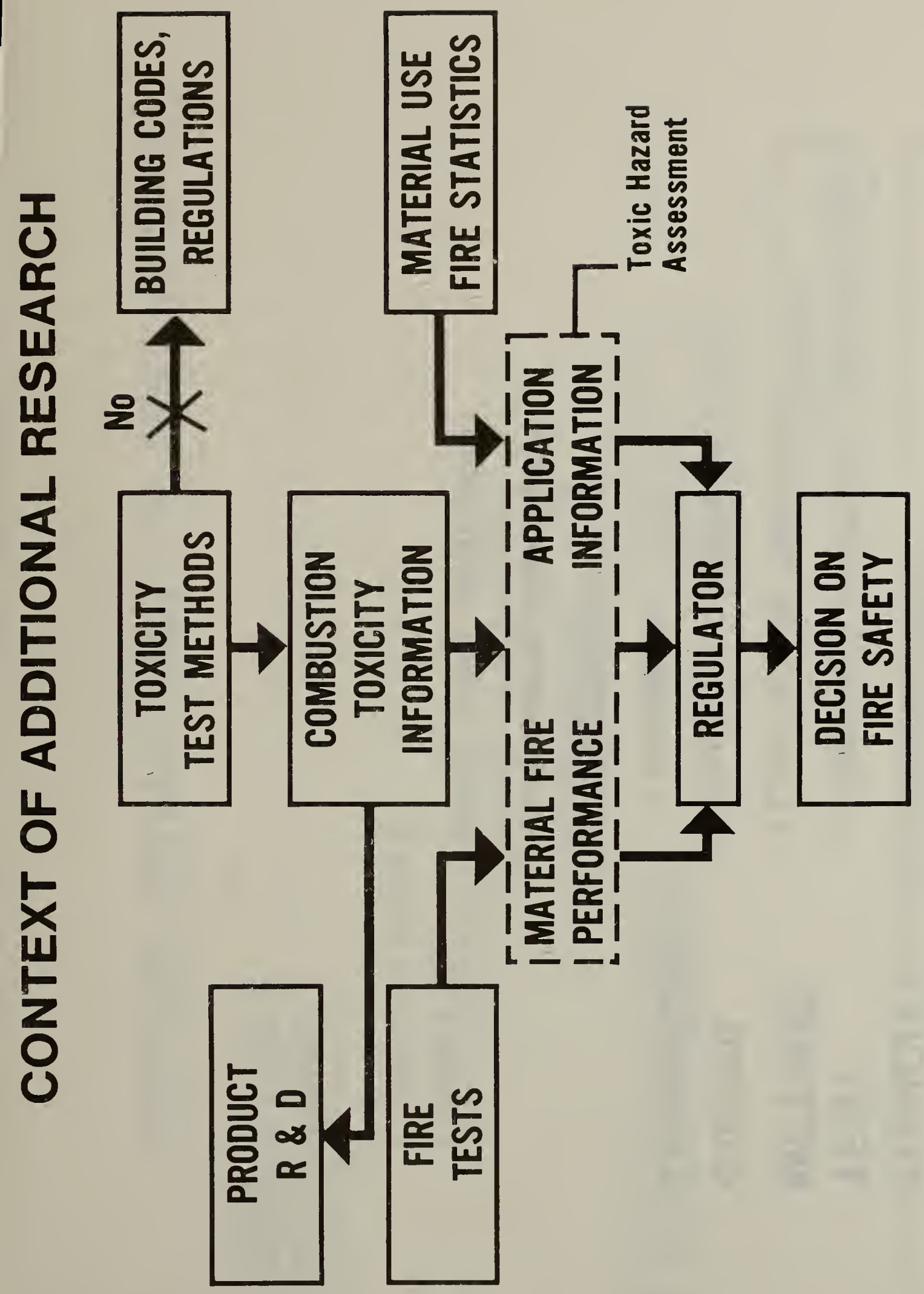




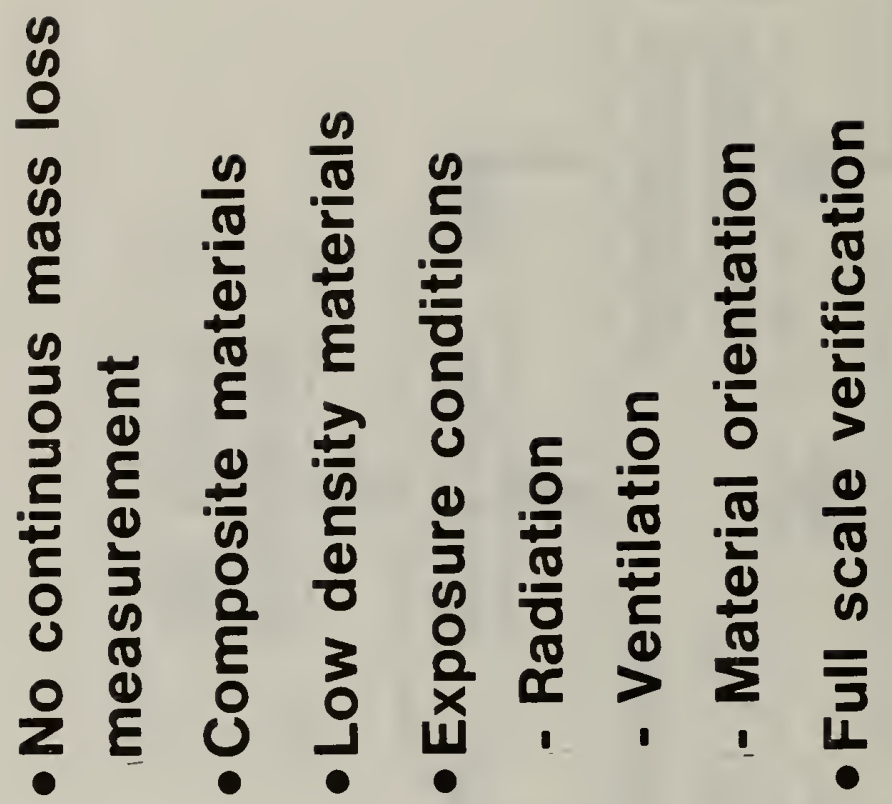

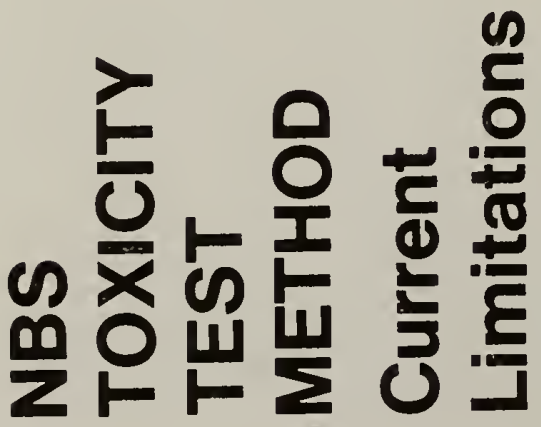




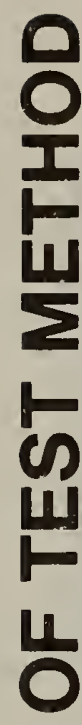

卢
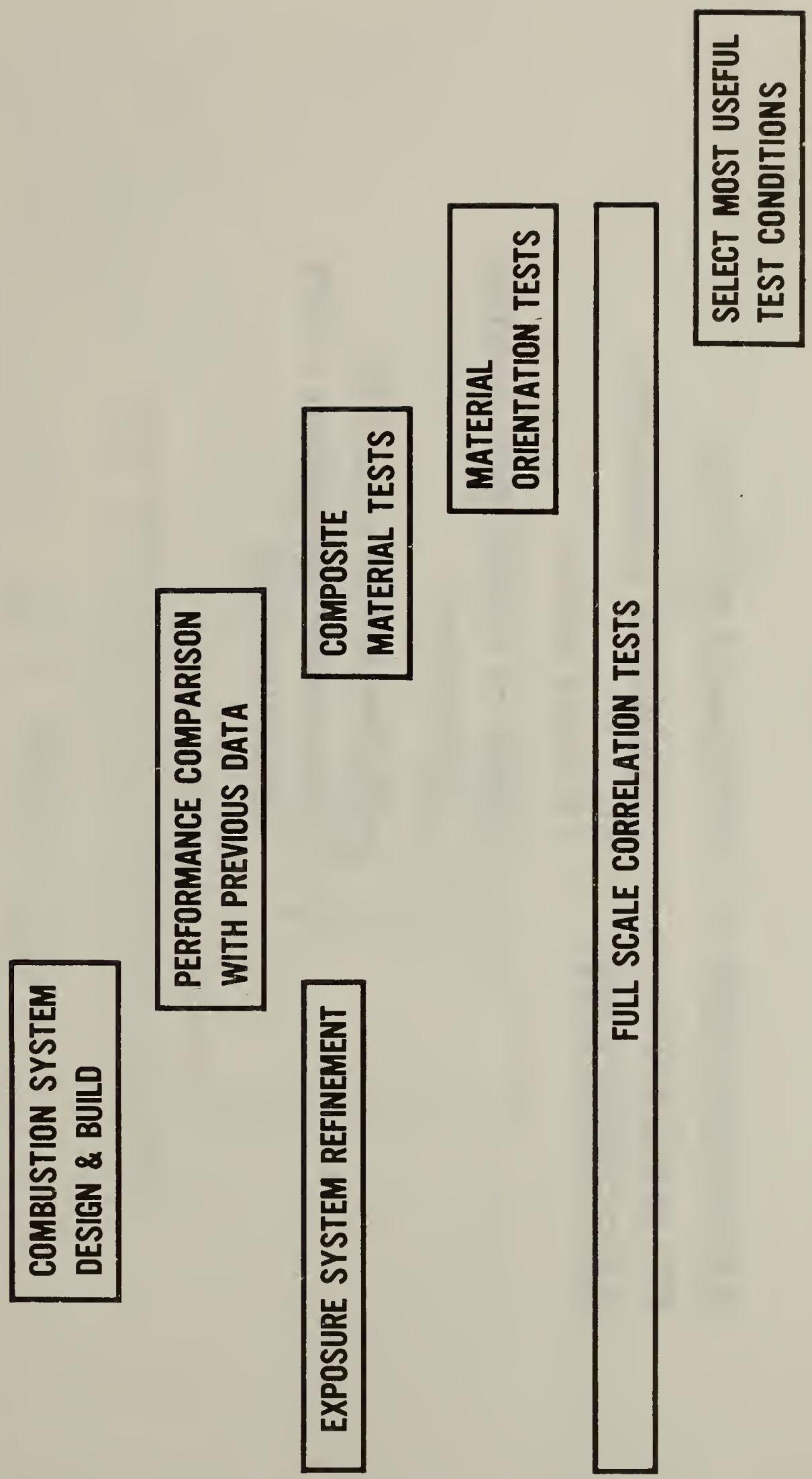

a

O

피

u

口

曲

ш

I

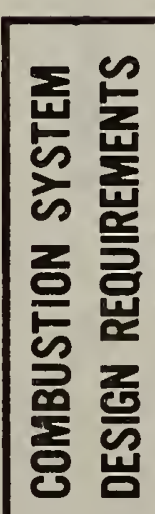




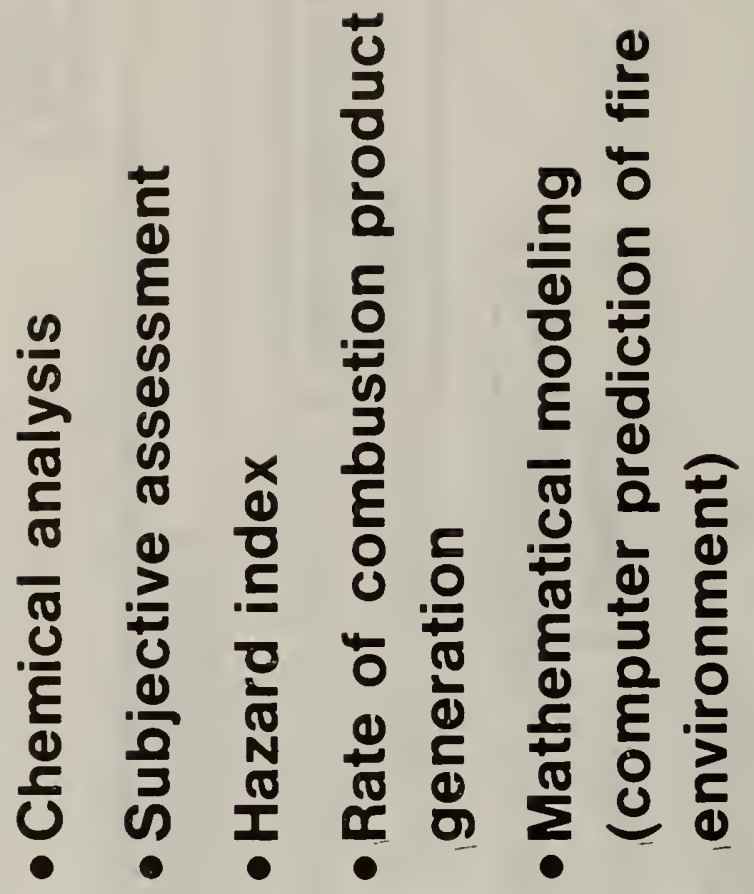

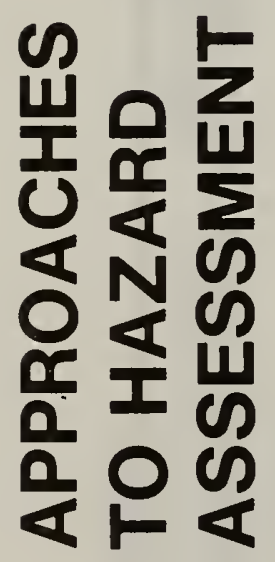




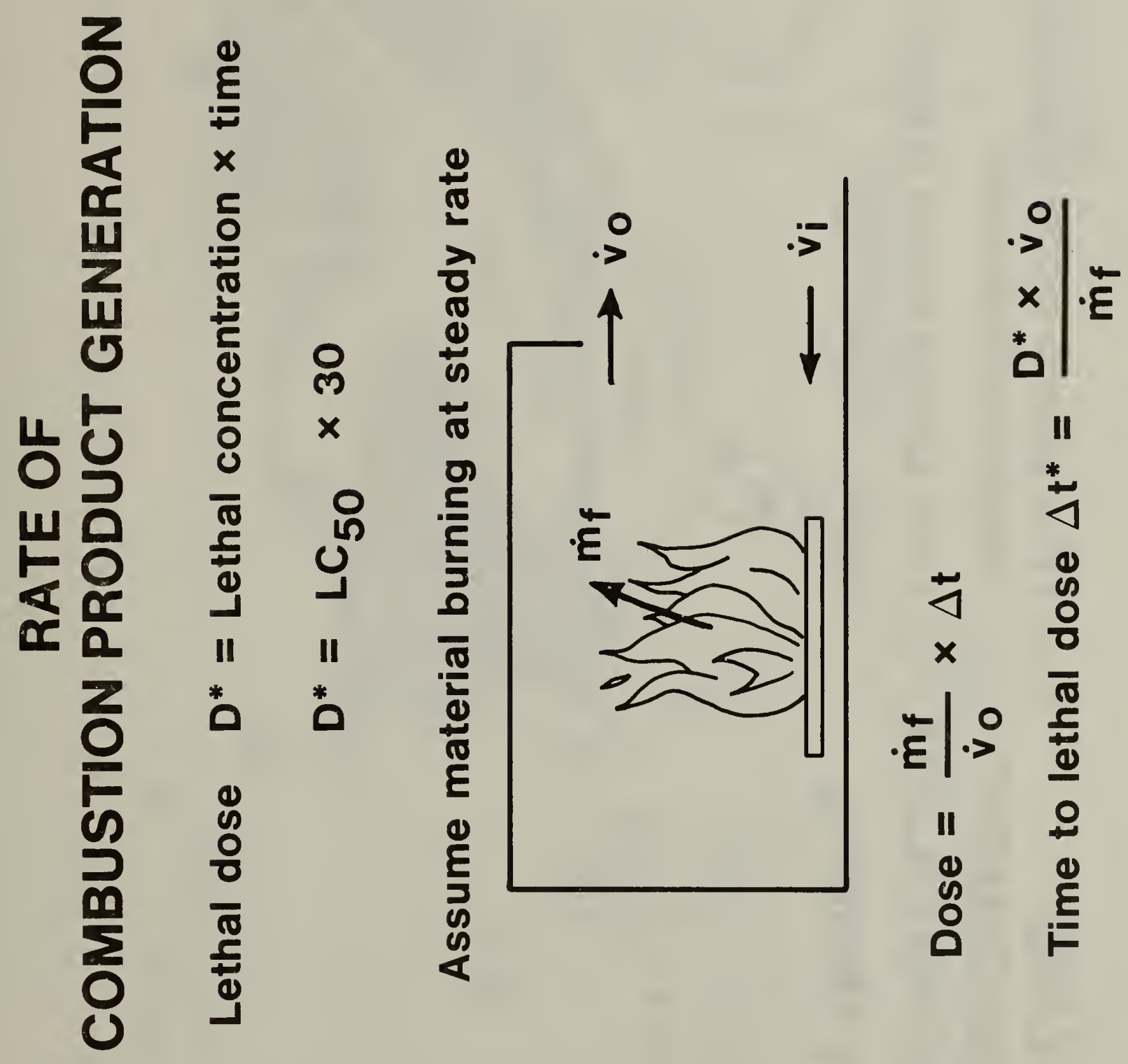



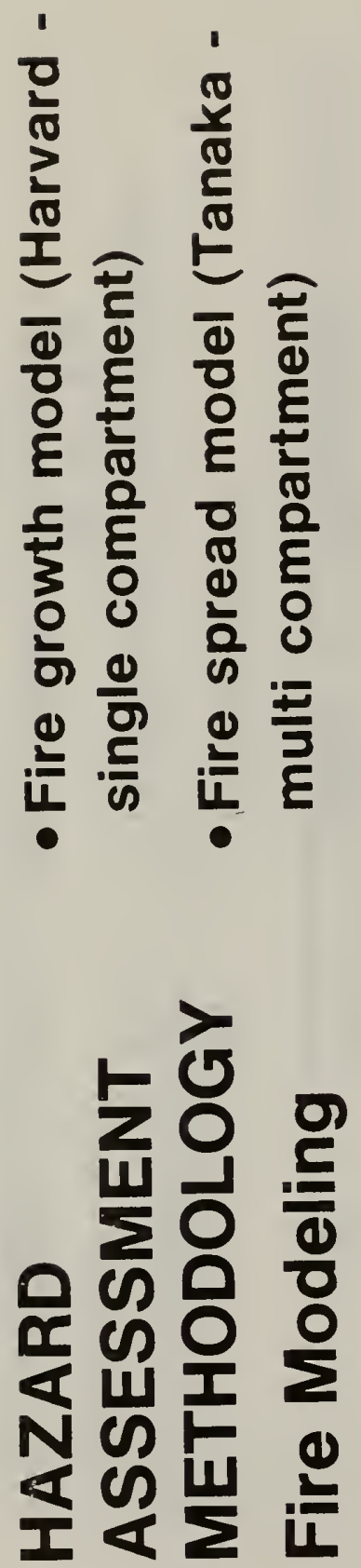


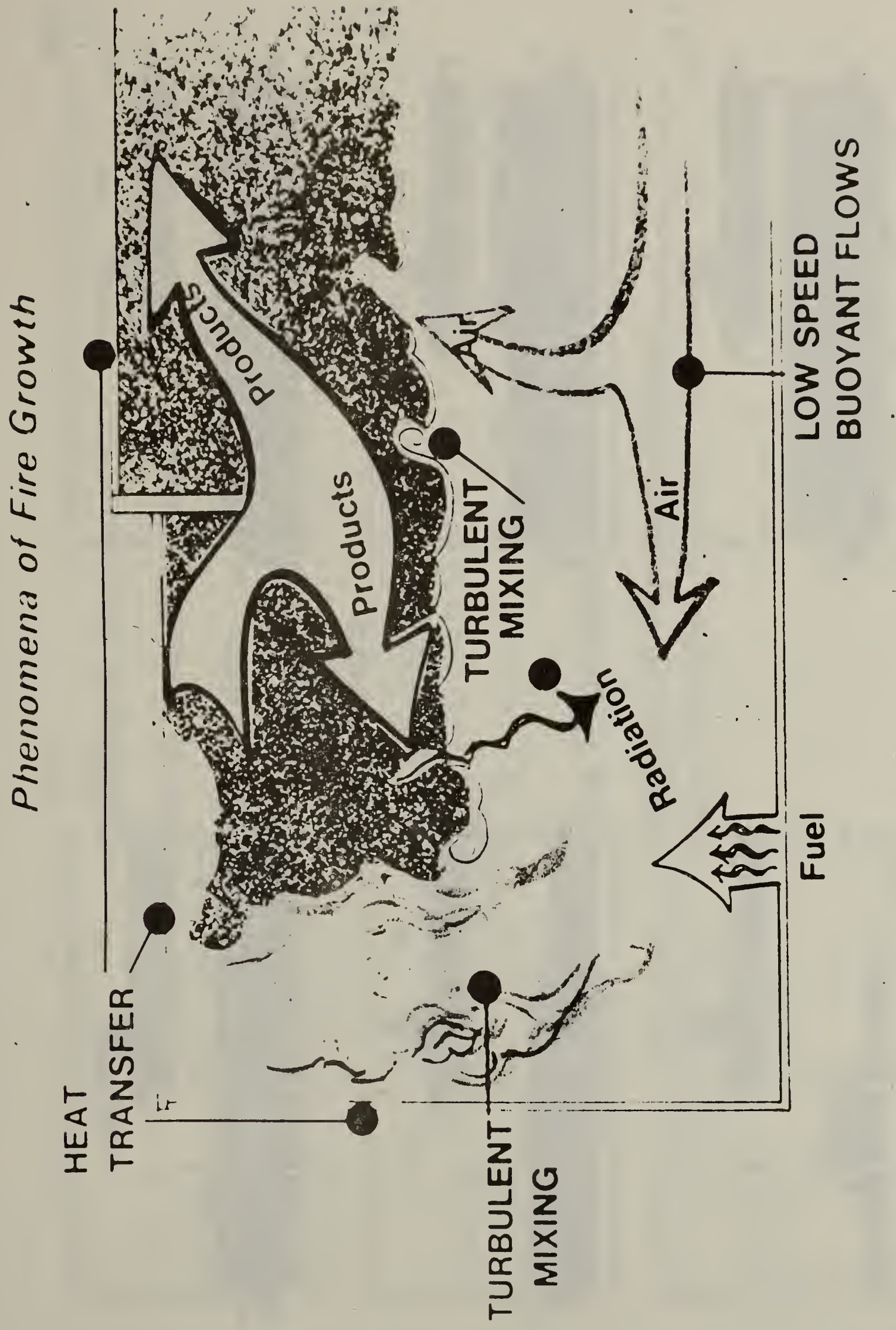


Slide 8
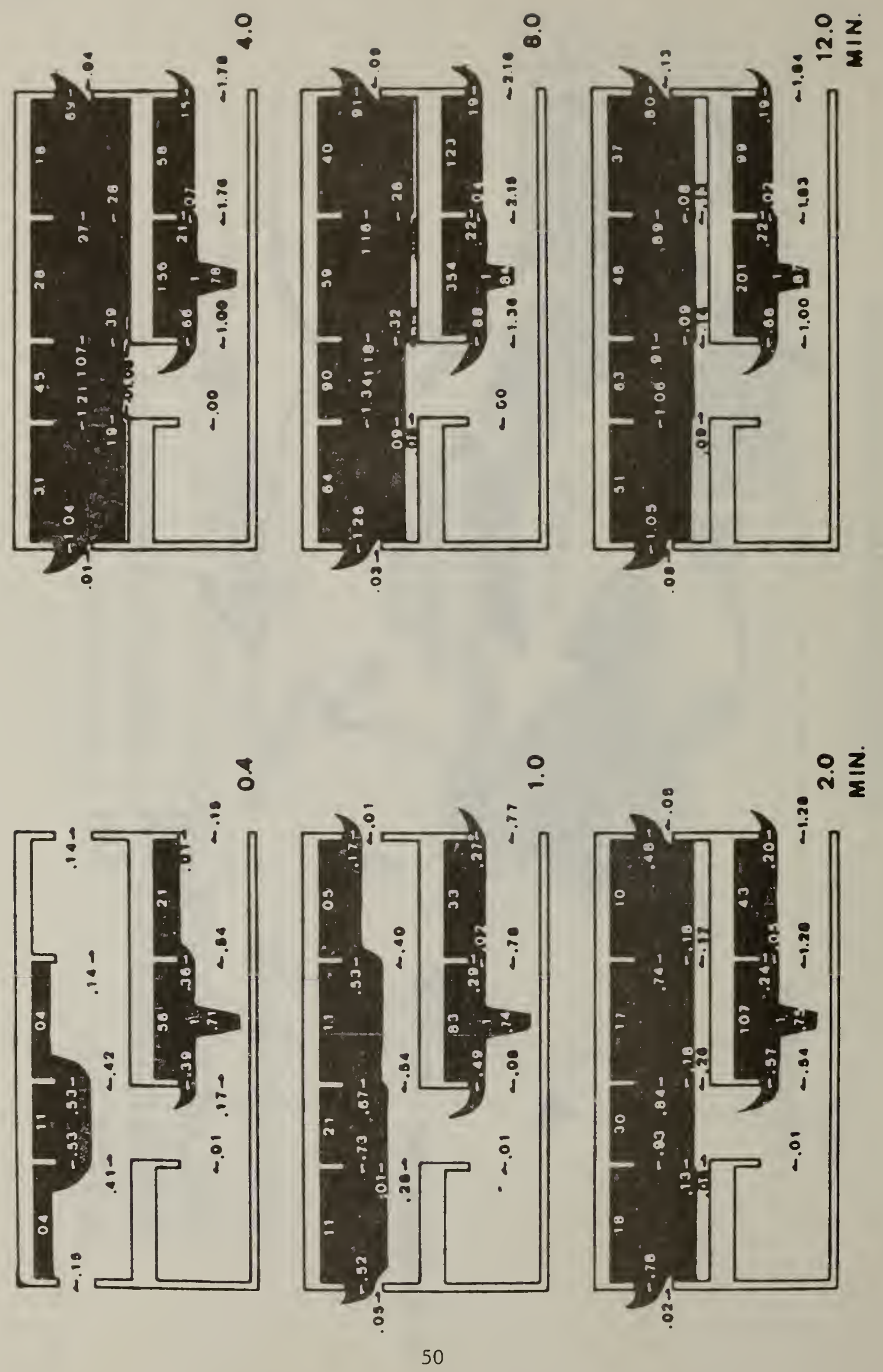
$\frac{U}{\mathbf{L}}$

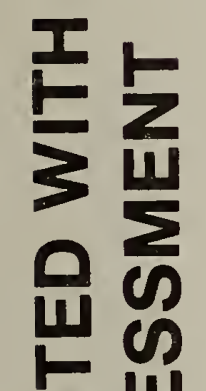

$\leftarrow$ U

00

$0<$

C 0

(2)

$<<$

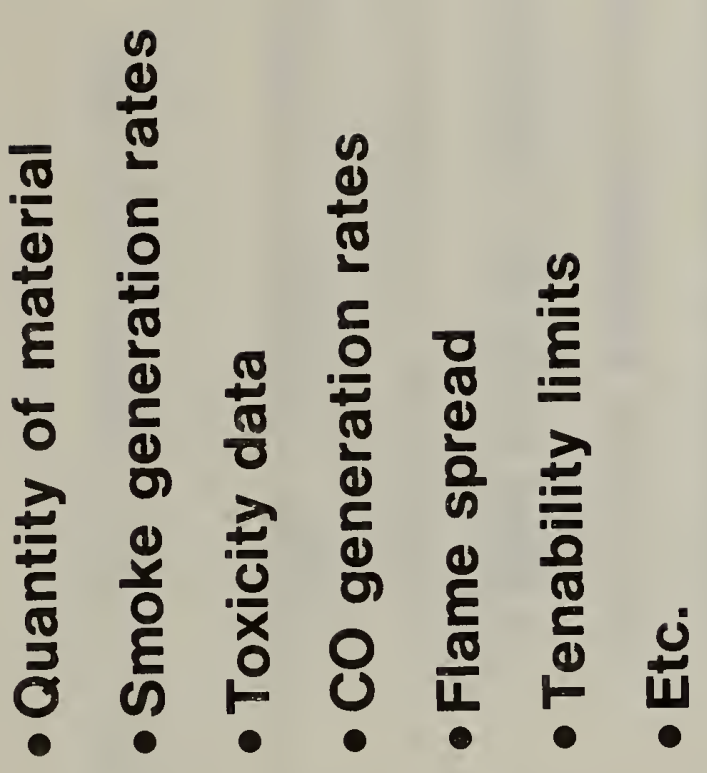

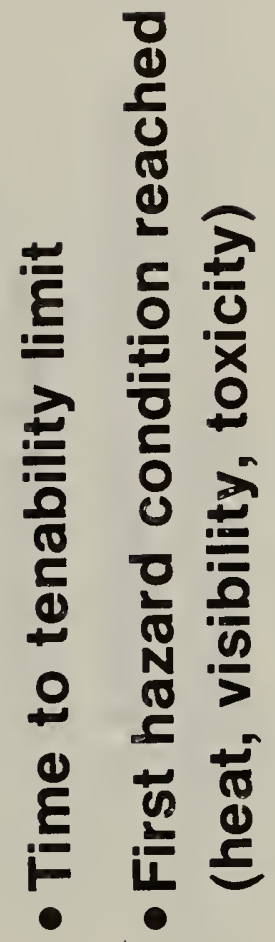

(S)

$0<$

0 I

4

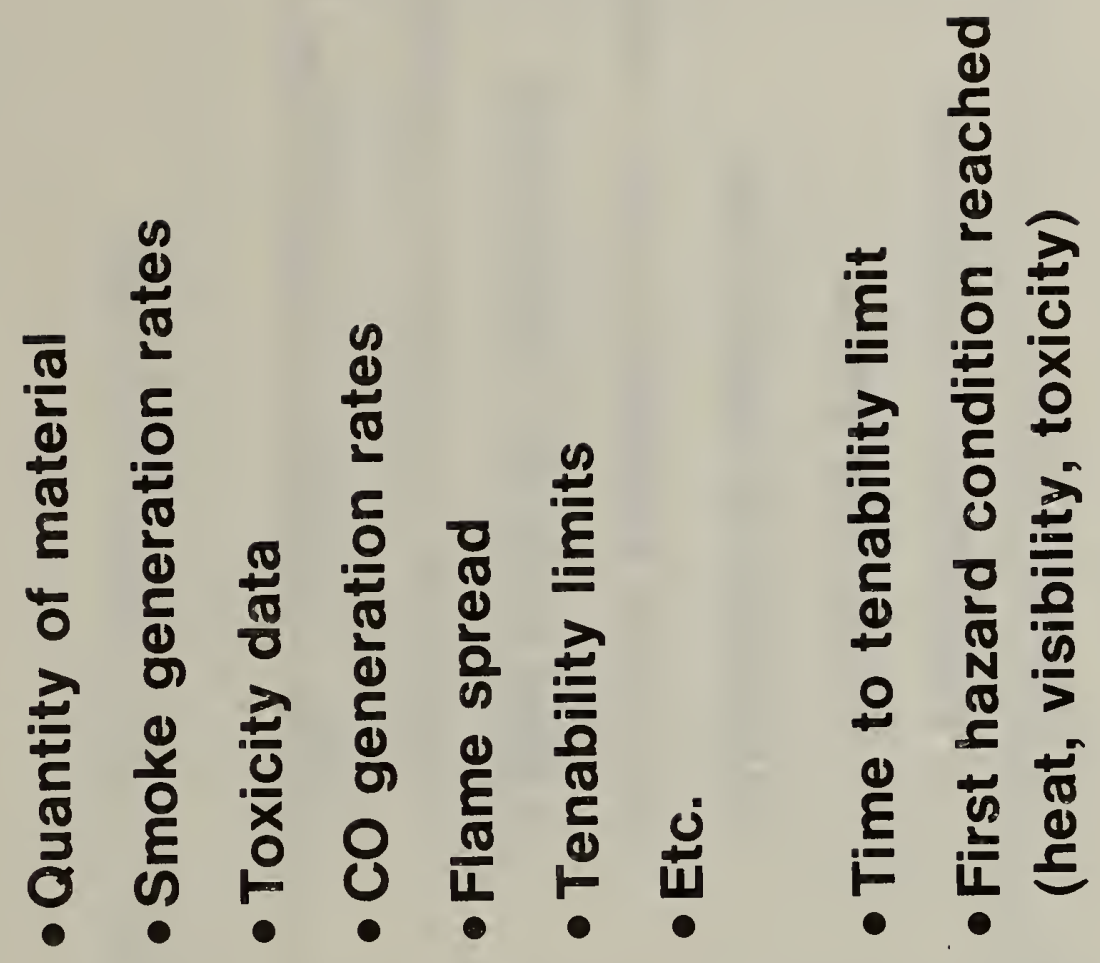

$\frac{1}{2}$

$\frac{5}{2}$ 

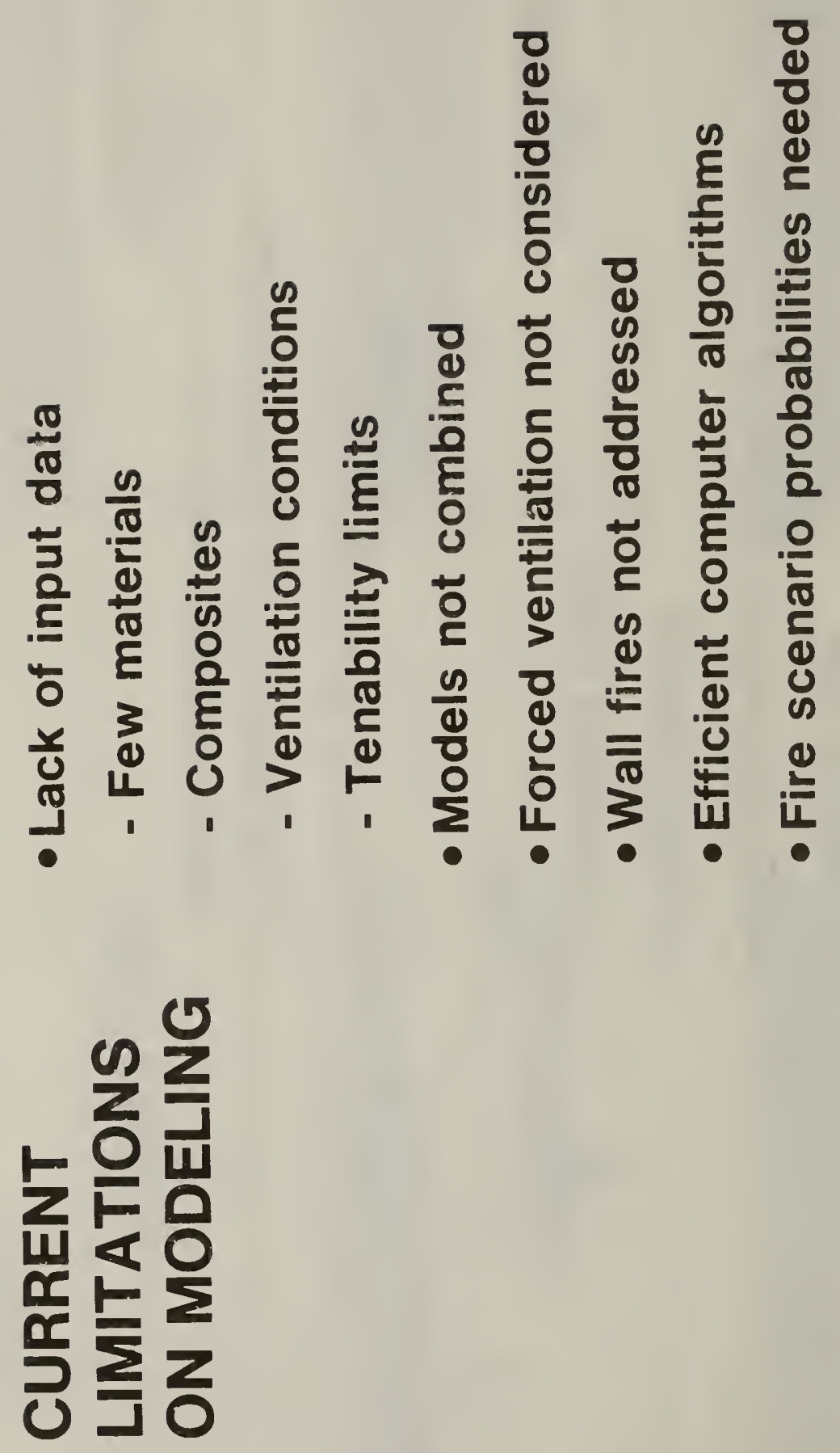


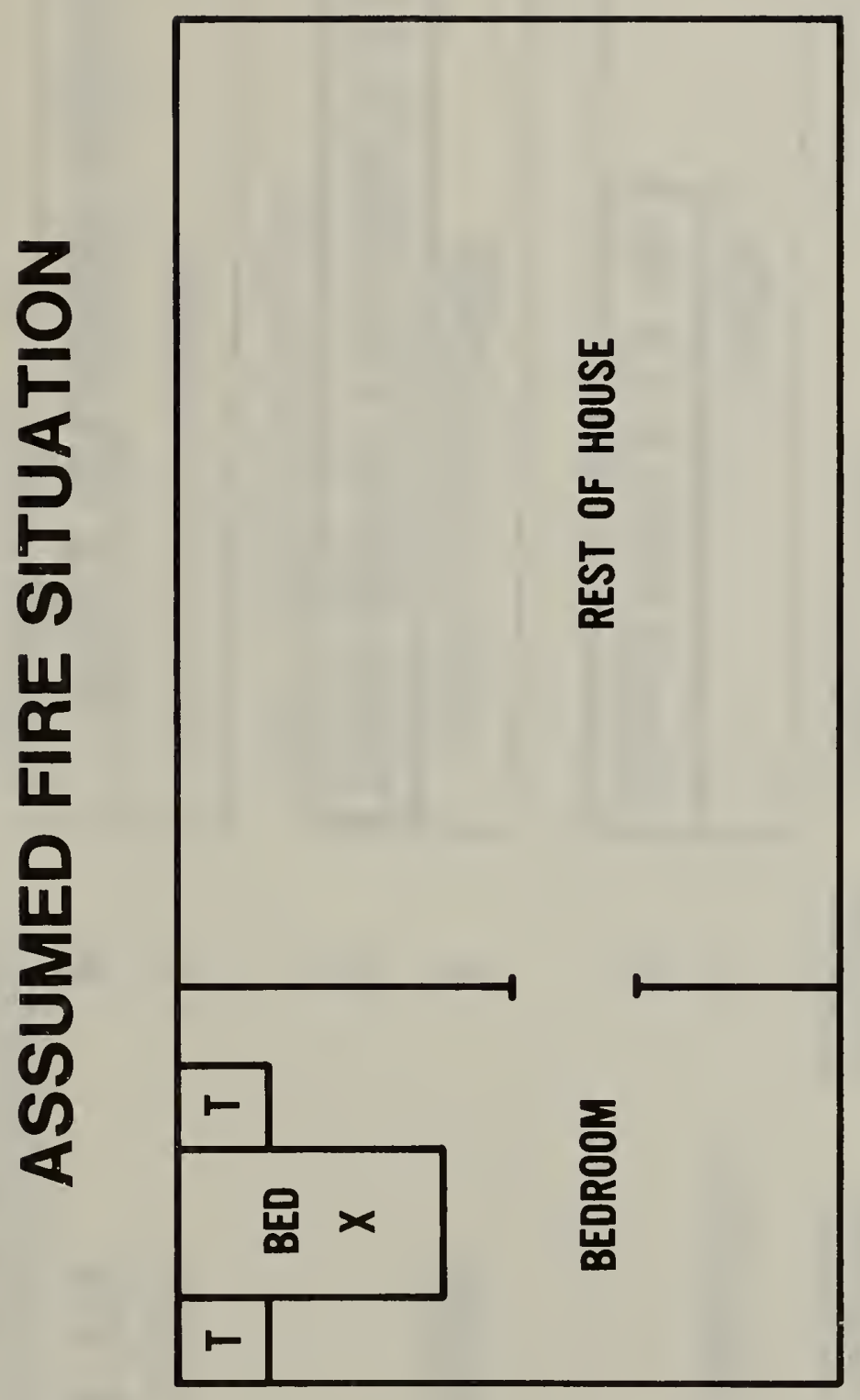


S1ide 12
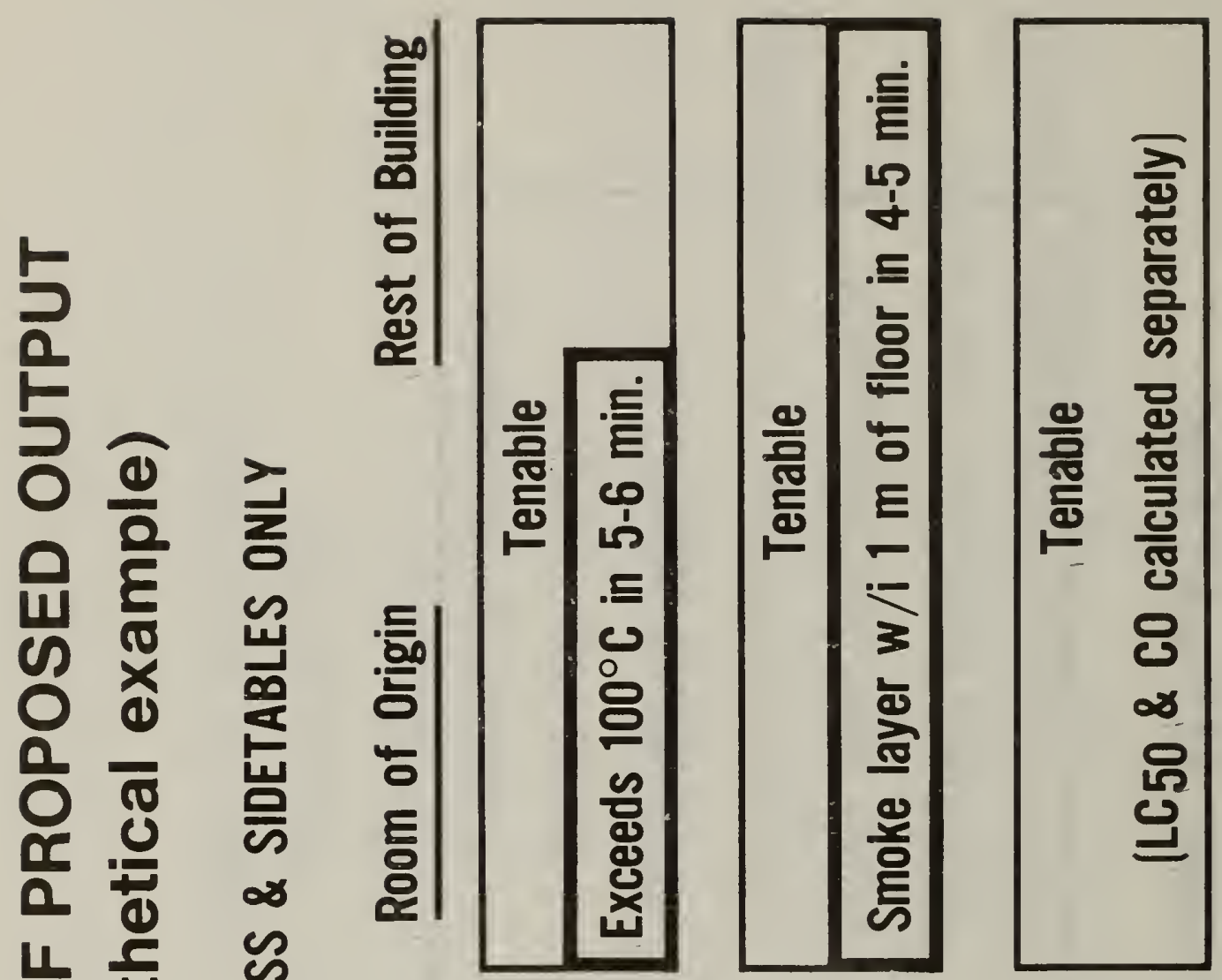

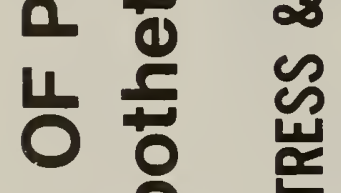

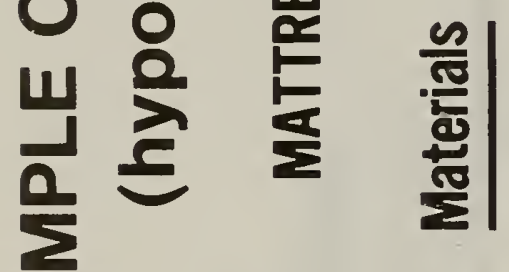

$-\infty$

$-\infty$

$-\infty$
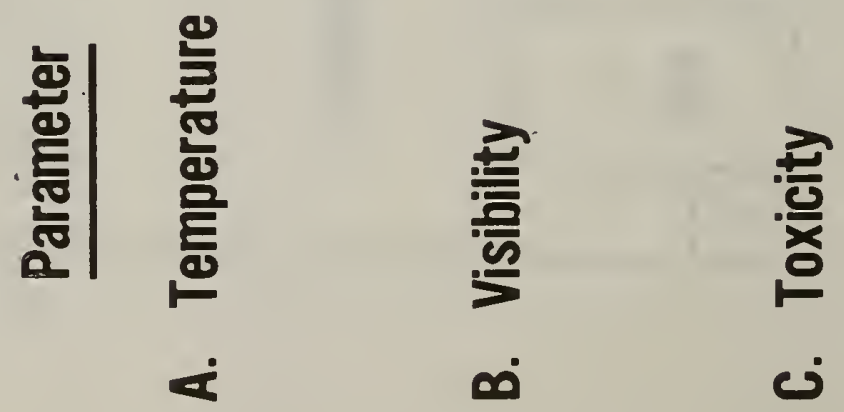

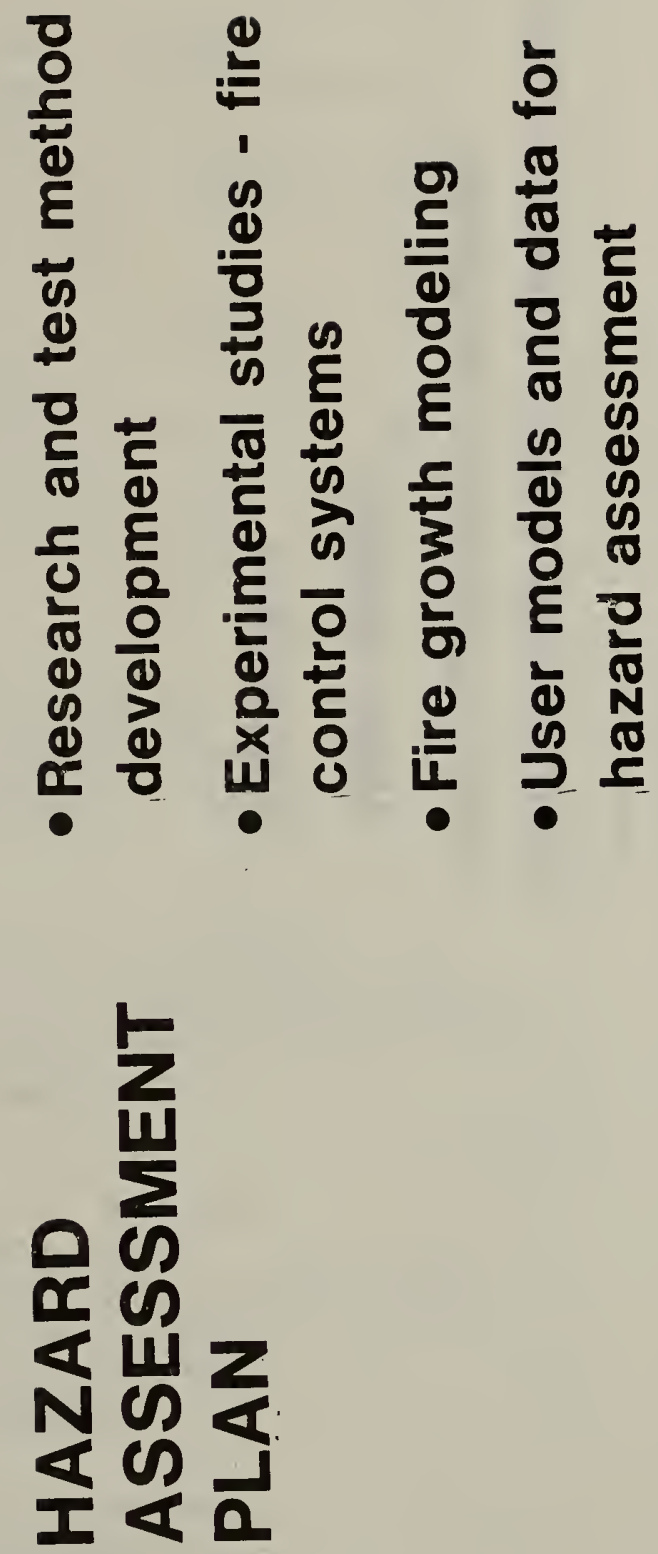

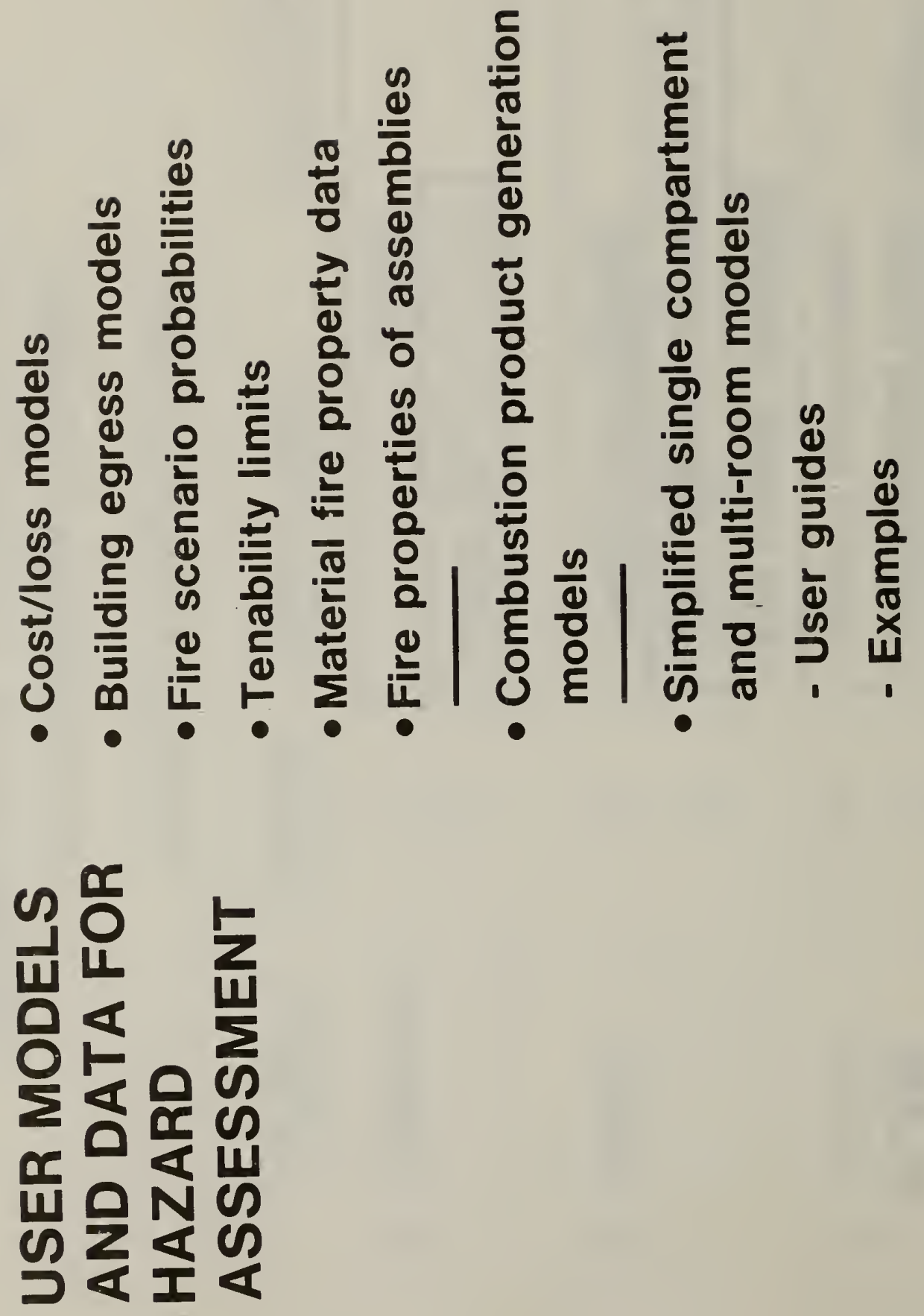


\title{
APPENDIX
}

\section{ATTENDANCE LIST}

\author{
National Bureau of Standards \\ Workshop on Combustion Product Toxicity \\ September 10, 1982
}

Dr. H. (Pat) Adams, Jr.

Technical Director

Man-Made Fiber Producers Assoc.

1150 17th Street, NW.

Washington, D.C. 20036

(202) 296-6508

Mr. Charles W. Almand

Manager, Governmental Services

U.S. Gypsum

105017 th Street, NW, Suite 1150

Washington, D.C. 20036

(202) 223-8266

Dr. Rosalind C. Anderson

Toxicologist

Arthur D. Little, Inc.

Acorn Park

Cambridge, MA 02140

(617) $864-5770$

Mr. Bruce D. Anson

Engineer

Rohm \& Haas Company

Independence Mall West

Philadelphia, PA 19107

(215) 592-3644

Mr. Bernard E. Auerbach

Manager, Standards Information

Allied Tube \& Conduit Corporation

16100 South Lathrop Avenue

Harvey, IL 60426

(312) 339-1610

Mr. Irwin A. Benjamin

Vice President

Benjamin/Clarke Associates, Inc.

10605 Concord Street

Kensington, MD 20895

(301) 949-1414

Mr. David W. Bensen

Program Manager

Federal Emergency Management Agency

500 C Street, SW.

Washington, D.C. 20472

(202) 287-3874
Mr. Jim Beyreis

Managing Engineer, Fire Protection

Underwriters Laboratories, Inc.

333 Pfingsten Road

Northbrook, IL 60062

(312) 272-8800 (x2301)

Dr. Merritt M. Birky

Director of Research

Foundation for Fire Safety

1700 North Moore Street, Suite 1508

Rosslyn, VA 22209

(703) 276-9222

Mr. Richard G. Bright

Fire Protection Engineer

Consultant

10303 Huron Court

Mt. Airy, MD 21771

(301) 831-9105

Mr. David J. Burkhart

Student-Fire Protection Engineering

University of Maryland

P.0. Box 223

College Park, MD 20740

(301) 434-2400

Mr. Robert W. Burns

Principal Engineer - Fire Protection

State of New Jersey, Bureau of

Construction Code Enforcement

363 West State Street

Trenton, NJ 08625

(609) 292-6254

Dr. Frederic B. Clarke

President

Benjamin/Clarke Associates, Inc.

10605 Concord Street

Kensington, MD 20895

(301) 949-1414

Mr. Eugene T. Cumberland

Codes Enforcement Officer

Codes Administration - Department of

Economic and Community Development

2525 Riva Road

Annapolis, MD 20714

(301) 269-2701 
Mr. Alvin D. Delman

Manager, Testing Services

The Wool Bureau, Inc.

225 Crossways Park Drive

Woodbury, NY 11797

(516) $364-0890$

Mr. Joseph G. DiPinto

Product Technology Manager

DuPont Company

11070 DuPont Building

Wilmington, DE 19898

(302) 774-7807

Mr. John C. Drinkard

Building Code Supervisor

State of Virginia

205 North Fourth Street

Richmond, VA 23219

(804) 786-5031

Mr. Daniel Drozdowski

Assistant Vice President

U.S. Testing Company

1415 Park Avenue

Hoboken, NJ 07030

(201) 792-2400 (x346)

Mr. W. A. Dunlap

Codes \& Standards Specialist

Dow Chemical Company

P.0. Box 515

Granville, OH 43023

(614) 587-4382

Prof. Irving Einhorn

Vice President

Center for Environmental and

Materials Research

1550 Asylum Avenue

West Hartford, CT 06117

(203) 233-6056

Mr. Wayne P. Ellis

Managex, Industry Standards

H. B. Fuller Company

P.0. Box 625

Spring House, PA 19438

(215) $628-2600$

Mr. Daniel J. Faingnaert

Technical Representative - Chemist

Stauffer Chemical Company

Grasslands Road

Elmsford, NY 10523

(914) 592-9010
Mr. John W. Fothergill, Jr.

President

Integrated Systems, Inc.

P.0. Box 128

Brunswick, MD 21716

(301) 834-7117/(703) 734-9057

Ms. Jane N. Fowler

Administrative Assistant

Upholstered Furniture Action Council

918 16th Street, NW., Suite 402

Washington, D.C. 20006

(202) $466-7362$

Mr. William R. Freeman, Jr.

Government \& Architectural Services

Koppers Company, Inc.

11724 Critton Circle

Woodbridge, VA 22192

(703) $690-3550$

Mr. Kenneth R. Frese

District Fire Protection Engineer

Office of State Fire Marshal (Virginia)

319 Landmark Towers

101 South Whiting Street

Alexandria, VA 22304

(703) 751-1008

Mr. Richard G. Gewain

Chief Fire Protection Engineer

American Iron and Steel Institute

1000 16th Street, NW.

Washington, D.C. 20036

(202) 452-7194

Mr. Robert W. Glowinski

Manager, Fire Technology

National Forest Products Association

1619 Massachusetts Avenue, NW.

Washington, D.C. 20036

(202) 797-5884

Mr. Tom Goonen

Senior Engineer

Schirmer Engineering Corporation

803 W. Broad Street

Falls Church, VA 22046

(703) 237-8211 
Ms. Cheryl Grounds

Student (Fire Protection Engineering)

University of Maryland

6864 Riverdale Road, 非101

Lanham, MD 20706

(301) 577-7851

Mr. Matthew T. Gustafson

Student (Fire Protection Engineering)

University of Maryland

43 Hatton Drive

Severna Park, MD 21146

(301) 647-4847

Mr. David M. Hammerman

Director

Codes Administration

2525 Riva Road

Annapolis, MD 21704

(301) 269-2701

Ms, Bea Harwnod

Statistician

U.S. Consumer Product Safety

Commission

5401 Westbard Avenue

Washington, D.C. 20207

(301) 492-6470

Mr. Marvin Hassman, P.E.

Director, Materials \& Equipment

Acceptance Division

Department of Buildings, City of

New York

120 Wall Street

New York, NY 10005

(212) 248-8817

Mr. Edward Heisnell

Associate Building Construction

Engineer

New York State Housing and Building

Codes Bureau

60th Floor, Two World Trade Center

New York, NY 10047

(212) 488-4912

Mr. Thomas M. Helscher

Manager, Regulatory Affairs

Monsanto Company

1101 17th Street, NW.

Washington, DC 20036

(202) 452-8880
Dr. Robert K. Hinderer

Senior Toxicologist

B. F. Goodrich Company

500 S. Main Street

Akron, OH 44318

(216) $374-4534$

Mr. Richard N. Hopper

Director of Governmental Affairs

Carpet \& Rug Institute

Suite $700,1629 \mathrm{~K}$ Street, NW.

Washington, D.C. 20006

(202) 223-2578

Mr. A. Larry Iseminger, Jr.

Fire Protection Engineer

Maryland State Fire Marshal's Office

301 West Preston Street

Baltimore, MD 21201

(301) 383-2522

Ms. Deborah Kale

Statistician

U.S. Consumer Product Safety

Commission

EPHA, Room 642

Washington, D.C. 20207

(301) 492-6470

Mr. Richard G. Katz

Fire Data Analyst

Federal Emergency Management Agency

500 C Street, SW.

Washington, DC 20472

(202) 287-0766

Mr. David Kay

Fire Prevention Engineer

Naval Sea Systems Command

Code $55 \times 32$

Washington, D.C. 20362

(202) 692-1242

Mr. Richard P. Kuchnicki

Executive Director

Council of American Building Officials

5205 Leesburg Pike, \#1201

Falls Church, VA 22041

(703) $931-4533$ 
Mr. Ronald J. Kunego

Foamwall Product Manager

E. G. Smith Division - Cyclops Corp. 100 Walls Street

Pittsburgh, PA 15042

(412) 761-7474 (x234)

Mr. Thomas E. Lewis

Manager, Govt. Tech. \& Mkt. Services

Armstrong World Industries, Inc.

1025 Connecticut Ave., NW., Suite 1007

Washington, D.C. 20036

(202) 296-2830

Mr. Larry Litchfield

Deputy Chief Engineer

State of Wisconsin DILHR

Safety \& Buildings Division

201 E. Washington Avenue

Madison, WI 53707

(608) 266-0675

Mr. George E. Maloney

Senior Engineering Consultant

The Travelers Insurance Company

7617 Little River Turnpike

Annandale, VA 22003

(703) $750-4196$

Mr. Francis A. McGarry

State Fire Administrator

N.Y.S. Office of Fire Prevention

162 Washington Avenue

Albany, NY 12231

(518) 473-3590

Mr. Lawrence A. McKenna, Jr.

Student (Fire Protection Engineering)

University of Maryland

11930 Beltsville Drive, \#14

Beltsville, MD 20705

(301) 572-2471

Mr. Don Moore

Architect

HUD

4517 th Street, SW.

Washington, D.C. 20410

(202) 755-6590

Mr. G. R. Munger

President

Society of the Plastics Industry, Inc.

355 Lexington Avenue

New York, NY 10017

(212) 573-9440
Mr. John Munno

Student (Fire Protection Engineering)

University of Maryland

4606 Beechwood Road

College Park, MD 20740

(301) 454-2436

Ms. Margaret L. Nelly

Chief, Flammability \& Textiles Branch

Engineering Sciences

Consumer Product Safety Commission

Room 735, WTB

Washington, D.C. 20207

(301) 492-6494

Dr. Rita Orzel

Chief, Toxicology Review Branch

Directorate for Health Sciences

Consumer Product Safety Commission

5401 Westbard Avenue

Bethesda, MD 20207

(301) 492-6994

Mr. Robert Robins

Chief Engineer

Hardwood Plywood Manufacturer's Assoc.

P.0. Box 2789

Reston, VA 22090

(703) 435-2900

Mr. H. J. Roux

Coordinating Manager

Armstrong World Industries, Inc.

Lancaster, PA 17604

(717) 397-0611

Mr. Van M. Seabaugh

Toxicologist

Consumer Product Safety Commission

200 C street, SW.

Washington, D.C. 20204

(202) 245-1445

Dr. L. J. Sharman

Fire Programs officer

Consumer Product Safety Commission

5401 Westbard Avenue

Bethesda, MD 20207

(301) 492-4554 
Mr. Tony Shaw

Manager of Technical Information

Hoechst Fibers Industries

P.0. Box 5887

Spartanburg, SC 29304

(803) 579-5382

Mr. Robert S. Strength

Product Safety \& Acceptability Manager Monsanto Plastics \& Resins Company

800 N. Lindbergh Blvd.

St. Louis, MO 63167

(314) 694-3211

Mr. Hugh Patrick Toner

Society of the Plastics Industry, Inc. 355 Lexington Avenue

New York, NY 10017

(212) 573-9422

Mr. H. F. Van Der Voort

Vice President, Industry Affairs

Carlon

23200 Chagrin Blvd.

Cleveland, OH 44122

(216) $831-4000$

Mr. William Wald

General Manager, Marketing

Tech. Services

Burlington Industries

Valley Forge Corp. Center

King of Prussia, PA 19406

(215) $666-7770$

Mr. Robert E. Warr

Consultant - Standards

General Electric

Fairfield, CT 06431

(203) 373-2288

Mr. Rodney L. Wells

Research Specialist, Polymer

Technology

Allied Corporation

P.O. Box 31

Petersburg, VA 23804

(804) 520-3621
Mr. Joseph G. Werner

Vice President

National Electrical Manufacturers Assoc. 2101 L. Street, NW.

Washington, D.C. 20037

(202) 457-8444

Mr. Franklin E. Williams

Division Lab. Manager

Burlington Industries

Anderson Street

Glasgow, VA 24555

(703) 258-2811

Mrs. Susan Womble

Chemist

Consumer Product Safety Commission

5401 Westbard Avenue

Bethesda, MD 20207

(301) 492-6994

Mr. Raymond S. Zielinski

Code Enforcement Specialist

N.Y.S. Office of Fire Prevention \& Control 162 Washington Avenue

Albany, NY 12231

(518) $474-6746$ 
1. PUBLICATION OR REPORT NO.

NBSIR $82-2634$

4. TITLE AND SUBTITLE

Workshop on Combustion Product Toxicity

Summary of Presentations, September 10, 1982

\section{AUTHOR(S)}

Jack E. Sne11, Barbara C. Levin, Andrew J. Fowe11

6. PERFORMING ORGANIZATION (If jolnt or other than NBS, see instructions)

7. Contract Grant No.

NATIONAL BUREAU OF STANDARDS

DEPARTMENT OF COMMERCE

8. Type of Report \& Period Covered

WASHINGTON, D.C. 20234

9. SPONSORING ORGANIZATION NAME AND COMPLETE ADDRESS (Street, CHY, StOT, ZIP)

10. SUPPLEMENTARY NOTES

Document describes a computer program; SF-185, FIPS Software Summary, is attached.

11. ABSTRACT (A 200-word or less foctual summary of most significant information. If document includes a significant bibliography or literature survey. mention it here) This publication is a summary of presentations given September 10, 1982, at a Workshop on Combustion Product Toxicity. Publicity on fire deaths caused by smoke and toxic gases has given impetus to a number of state legislatures to consider requiring material toxicity provisions in building codes and other regulations. The National Bureau of Standards recently published a technical report describing the development of a test method for the assessment of the acute inhalation toxicity of combustion products. This test method is intended primarily for research and for preliminary screening purposes by product researchers and material manufacturers in developing and evaluating materials. The test method is not intended to be used itself in evaluating the suitability of a material for specific application since additional factors must be considered. Therefore, the National Bureau of Standards sponsored a half-day workshop on combustion product toxicity, 9:00 a.m. 12:00 noon, Friday, September 10, 1982, at NBS in Gaithersburg, Maryland. The purpose of this meeting was to brief fire code and building officials and others on the NBS test method for assessing acute inhalation toxicity of combustion products and to provide an opportunity for discussion of its appropriate use.

12. KEY WORDS (Six to twelve entries: alphabetical order: capitalize only proper names; and separate key words by semicolons) building codes; combustion products; fire growth modeling; hazard assessment; inhalation; materials; test method; toxicity.

13. AVAILABILITY

[X] Unlimited

For Official Distribution. Do Not Release to NTIS

Order From Superintendent of Documents, U.S. Government Printing Office, Washington, D.C. 20402.

[x] Order From National Technical Information Service (NTIS), Springfield, VA. 2216I
14. NO. OF PRINTED PAGES

65

15. Price

$\$ 9.00$ 

. 